\title{
Identification of main-effect quantitative trait loci (QTLs) for low-temperature stress tolerance germination- and early seedling vigor-related traits in rice (Oryza sativa L.)
}

\author{
S. Najeeb • J. Ali $(\mathbb{D} \cdot$ A. Mahender • Y.L. Pang • J. Zilhas • V. Murugaiyan • \\ Lakshminarayana R. Vemireddy $\cdot$ Z. Li
}

Received: 21 January 2019 / Accepted: 12 December 2019/Published online: 4 January 2020

(C) The Author(s) 2020

\begin{abstract}
An attempt was made in the current study to identify the main-effect and co-localized quantitative trait loci (QTLs) for germination and early seedling growth traits under low-temperature stress (LTS) conditions in rice. The plant material used in this study was an early backcross population of 230 introgression lines (ILs) in $\mathrm{BC}_{\mathrm{I}} \mathrm{F}_{7}$ generation derived from the Weed Tolerant Rice-1 (WTR-1) (as the recipient) and Haoannong (HNG) (as the donor). Genetic analyses of LTS tolerance revealed a total of 27 main-effect quantitative trait loci (M-QTLs) mapped on 12 chromosomes. These QTLs explained more than $10 \%$ of phenotypic variance (PV), and average PV of $12.71 \%$ while employing 704 high-quality SNP markers. Of these 27 QTLs distributed on 12 chromosomes, 11 were
\end{abstract}

Electronic supplementary material The online version of this article (https://doi.org/10.1007/s11032-019-1090-4) contains supplementary material, which is available to authorized users.

S. Najeeb $\cdot$ J. Ali $(\bowtie) \cdot$ A. Mahender $\cdot$ J. Zilhas $\cdot$

V. Murugaiyan

Rice Breeding Platform, International Rice Research Institute (IRRI), 4031 Los Baños, Laguna, Philippines

e-mail: J.Ali@irri.org

S. Najeeb

Mountain Research Centre for Field Crops, Sher-e-Kashmir University of Agricultural Science \& Technology (SKAUST), Khudwani, Kashmir 190025, India

Y. Pang

State Key Laboratory of Crop Biology, College of Agronomy, Shandong Agricultural University, Taian 271018, People's Republic of China associated with low-temperature germination (LTG), nine with low-temperature germination stress index (LTGS), five with root length stress index (RLSI), and two with biomass stress index (BMSI) QTLs, shoot length stress index (SLSI) and root length stress index (RLSI), seven with seed vigor index (SVI), and single QTL with root length (RL). Among them, five significant major QTLs $\left(q L T G(I)_{1}, q L T G S(I)_{1-2}, q L T G(I)_{5}\right.$, $q L T G S(I)_{5}$, and $\left.q L T G(I)_{7}\right)$ mapped on chromosomes 1 , 5, and 7 were associated with LTG and LTGS traits and the PV explained ranged from 16 to $23.3 \%$. The genomic regions of these QTLs were co-localized with two to six QTLs. Most of the QTLs were growth stage-specific and found to harbor QTLs governing multiple traits. Eight chromosomes had more than four QTLs and were

\begin{abstract}
V. Murugaiyan
Plant Nutrition, Institute of Crop Sciences and Resource Conservation (INRES), University of Bonn, 53012 Bonn, Germany
\end{abstract}


clustered together and designated as promising LTS tolerance QTLs (qLTTS), as $q L T T_{1}, q L T T_{2}, q L T T_{3}$, $q L T T_{5}, q L T T_{6}, q L T T_{8}, q L T T_{9}$, and $q L T T_{11}$. A total of 16 putative candidate genes were identified in the major M-QTLs and co-localized QTL regions distributed on different chromosomes. Overall, these significant genomic regions of M-QTLs are responsible for multiple traits and this suggested that these could serve as the best predictors of LTS tolerance at germination and early seedling growth stages. Furthermore, it is necessary to fine-map these regions and to find functional markers for marker-assisted selection in rice breeding programs for cold tolerance.

Keywords Low-temperature stress · Germination · Early seedling growth stage $\cdot$ Stress index $\cdot$ SNP markers · Quantitative trait loci

$\begin{array}{ll}\text { Abbreviations } \\ \text { ILs } & \text { Introgression lines } \\ \text { SNP } & \text { Single nucleotide } \\ & \text { polymorphism. } \\ \text { LTS } & \text { Low-temperature stress. } \\ \text { BC } & \text { Backcross breeding. } \\ \text { QTL } & \text { Quantitative trait loci } \\ \text { MAS } & \text { Marker-assisted selection }\end{array}$

\section{Introduction}

Rice (Oryza sativa L.) is one of the primary food crops for more than 3.5 billion people, about half of the global population, and it provides $19 \%$ of the dietary energy and $20 \%$ of the dietary protein in developing countries (http://ricepedia.org). A total of $90 \%$ of the production and consumption of global rice is contributed by Asian countries, with India and China alone accounting for 55 $\%$ of rice production (Milovanovic and Smutka 2017). However, rice production has a significant impact on global climatic variations through different factors such as water, soil nutrients, temperature, air pollution, and loss of biodiversity, which threaten global food security and sustainability. The Food and Agriculture Organization of the United Nations (FAO) estimates that global food production must be increased by $70 \%$ by 2050 to meet the food requirements for the estimated global population of $\sim 9.7$ billion in 2050 (www.fao. org). In addition to that, several major biotic and abiotic stress factors significantly influence crop yield. Importantly, abiotic stresses such as drought, submergence, high temperature, cold/low temperature, and salinity directly or indirectly affect the physiological status of rice and negatively alter its overall genetic mechanisms and metabolism, often with negative impacts on yield (Wani et al. 2016; Meena et al. 2017; Abhinandan et al. 2018; Sahebi et al. 2018). More than $50 \%$ of plant productivity often becomes decreased by various abiotic stresses, which have effects individually or in combination, leading to an alteration in plant growth metabolism and development (Rejeb et al. 2014; Singhal et al. 2016). Compared with other cereal crops, rice is more sensitive to low-temperature stress (LTS)/cold stress (CS) as it has originated from tropical regions (Saito et al. 2001; Hasanuzzaman et al. 2009; Zeng et al. 2017). In the temperate, tropical, and even subtropical rice-growing regions, cold stress adversely affects the rice crop throughout various growth stages, from germination to harvesting, and causes significant yield losses because of poor germination and seedling establishment, stunted growth pattern, non-vigorous plants, vast spikelet sterility, delay in flowering, and lower grain filling (Ranawake et al. 2014; MartínezEixarch and Ellis 2015; Schläppi et al. 2017; Shakiba et al. 2017; Liang et al. 2018; Xiao et al. 2018; Najeeb et al. 2019 (unpublished). Therefore, to minimize these yield losses, particularly in cold-affected regions, it is imperative to identify and develop high-yielding rice cultivars showing tolerance of LTS.

The optimum temperature requirement for rice cultivation ranges between 25 and $35^{\circ} \mathrm{C}$ (Nagai and Makino 2009; Luo 2011). Uniform fast seed germination and early seedling vigor are important traits for seedling establishment. However, most rice varieties are severely affected during early seedling growth when the temperature falls below $17{ }^{\circ} \mathrm{C}$ (Andaya and Mackill 2003a; Lou et al. 2007; Ranawake et al. 2014; Singh et al. 2016). For better and more stable stand establishment, especially under direct-seeding conditions in temperate and sub-temperate regions, cold tolerance at germination is a pre-requisite (Teng et al. 2001; Cruz and Milach 2004; Wang et al. 2016a). Numerous reports have mentioned growth stage-specific criteria to evaluate and select LTS-tolerant rice cultivars (reviewed by Najeeb et al. (2019) unpublished). With the unpredictable changes in the climatic scenario, LTS causes an average yield reduction of $5-10 \%$ and sporadically as much as $20-40 \%$ in temperate and high-altitude environments 
largely in Asia, Australia, Africa, Europe, and South and North America (Sthapit and Witcombe 1998; Anbumozhi et al. 2012; Zeng et al. 2017). Worldwide, more than 15 million ha of rice suffer from cold damage at one or more growth stages (Zhang et al. 2014a). Phenotypic evaluation of rice cultivars typically has been studied during the seedling and booting stages that are critical to rice production, particularly in the temperate and high-latitude or high-altitude regions. However, LTS can severely affect the germination rate and early seedling growth (Zhang et al. 2014a). Therefore, phenotypic evaluation of LTS tolerance at the germination stage is especially significant for these regions.

As compared with indica, temperate japonica rice cultivars are LTS tolerant, but the tolerance mechanism is manifested only at specific growth stages (Glaszmann et al. 1990; Saito et al. 2001; Wang et al. 2016b; Pradhan and Rani 2017). Several rice cultivars with a high degree of LTS tolerance have been bred and released in China, India, the USA, Australia, Japan, Vietnam, Iran, Korea, and Egypt (Ye et al. 2009; da Cruz et al. 2013; Bonnecarrere et al. 2015; Donoso et al. 2015). However, this significant achievement in LTS tolerance has been made only in the japonica subspecies. Therefore, developing indica cold-tolerant rice cultivars has remained an vital breeding objective, particularly in temperate and sub-temperate target environments (da Cruz et al., 2013; Zhang et al. 2014a; Sales et al. 2017), and it is still a big challenge to plant breeders and biotechnologists.

Conventional plant breeding has achieved partial success in developing LTS-tolerant crops because of the complexity of stress tolerance traits, the low genetic variance of yield-attributing components under stress conditions, and the lack of efficient selection criteria (Sanghera et al. 2011; Singh et al. 2016). Therefore, it is imperative to find complementary strategies to conventional breeding methodologies such as molecular marker technologies, linkage maps, and advanced genomic tools to develop LTS-tolerant rice cultivars. LTS tolerance in rice is a very complex and polygenic trait that is genetically controlled by multiple QTLs. Several LTS tolerance QTLs have been mapped on different genomic regions distributed on all 12 rice chromosomes using various types of molecular markers such as RFLP, AFLP, SSR, STS, and SNP, which has facilitated the identification of chromosomal regions associated with tolerance of low temperature (Andaya and Tai 2006; Lou et al. 2007; Ji et al. 2010; Ye et al. 2010; Jena et al. 2012; Verma et al. 2014; Satoh et al. 2016; Wang et al. 2016a; Jiang et al. 2017).

To date, more than 550 QTLs have been reported for different growth stages (germination, seedling, and reproductive/booting stage) for tolerance of LTS by using DNA-based molecular markers on different genetic backgrounds derived from bi-parental mapping populations and diverse genetic resources of rice accessions (Liang et al. 2018; Najeeb et al. (2019) unpublished). Mapping of the stable QTLs for LTS at the reproductive/booting stage is more of a major challenge than at the seedling stage because of difficulties in accurate phenotypic screening and also the complexity of molecular genetics and physiological pathways. Liang et al. (2018) noted more than 100 QTLs responsible for cold tolerance, particularly in the booting stage. However, despite further progress in the molecular genetic dissection of LTS tolerance in rice, few of them were confirmed to be stable QTLs across environments (Fujino et al. 2008; Ji et al. 2010; Li et al. 2013; Cui et al. 2013; Kim et al. 2014; Zhu et al. 2015). With the development of advanced genomics and molecular marker technology, six QTLs ( $q$ CTS-9, qCT8, qCTB7, $q C T B 3, q C T-3-2$, and $q C T B 10-2)$ have been finemapped via a map-based cloning approach and only two QTLs (Ctb1 and CTB4a) have been cloned and functionally conferred to LTS (Kuroki et al. 2007; Saito et al. 2010; Zhou et al. 2010; Shirasawa et al. 2012; Zhu et al. 2015; Li et al. 2018; Sun et al. 2018). However, even with the different genetic backgrounds of rice germplasm, QTLs for stage-specific cold tolerance were mapped on different locations on the 12 chromosomes. Several researchers have been using different temperature regimes ranging from 4 to $28^{\circ} \mathrm{C}$ for cold tolerance screening while employing diverse rice germplasm and bi-parental mapping populations, and they have reported several vegetative- and reproductive-stage QTLs for cold tolerance (Fujino and Matsuda 2010; Suh et al. 2010; Jiang et al. 2011; Park et al. 2013; Zhu et al. 2015; Pan et al. 2015; Shakiba et al. 2017; Zhao et al. 2017; Liang et al. 2018; Sun et al. 2018; Xiao et al. 2018). Through genome-wide association studies (GWAS) approaches, 97 QTLs were identified for LTS tolerance at the germination stage (Pan et al. 2015; Sales et al. 2017; Schläppi et al. 2017). In a similar way, 211 QTLs for seedling-stage tolerance and 72 QTLs for booting-stage tolerance were identified while using diverse rice genetic resources (Pan et al. 2015; Lv et al. 2016; Wang et al. 
2016a; Shakiba et al. 2017; Xiao et al. 2018; Zhang et al. 2018b).

Despite the progress in LTS tolerance in rice, few QTLs mapped or cloned have been used in breeding programs due to the possible effects of epistasis and QTL $\times$ environment interactions (Li 2001). The major drawback of a breeding program for the development of LTS tolerance is expressed by the inconsistency across varying environments, the huge technical gap between screening in growth chambers and field experiments for quantitatively inherited traits, and the lack of suitable donors (Nagano 1998; Zhang et al. 2014b). Lowtemperature germination ability plays a vital role in the success of rice cultivation in temperate and subtemperate regions. Despite the existence of a considerable amount of genetic variation for germination under LTS, most breeding programs were not able to make any significant breakthrough, possibly because the trait is genetically complex.

To overcome problems in the breeding and molecular dissection of LTS, we have been using an early backcross breeding strategy as green super rice breeding technology (GSR-BT) with selective introgression lines, which we have been using for dissecting for many complex traits and this has been successful in many applications (Ali et al. 2016, 2018; Li et al. 2016; Dimaano et al. 2017; Pang et al. 2017; Feng et al. 2018; Liang et al. 2018). Here, we mainly focused on two targets: (i) development of trait-specific introgression lines (ILs) via an early backcross breeding (BC) approach, and (ii) dissection of the molecular genetics of LTS tolerance traits using the ILs and $6 \mathrm{~K}$ genotyping. In the present study, we used a total of $230 \mathrm{BC}_{1} \mathrm{~F}_{7}$ ILs derived from the Weed Tolerant Rice1 (WTR-1) as a recipient parent and Haoannong (HNG) as a donor parent, which were evaluated for LTS tolerance at germination and post-germination stages. Here, we discuss the QTLs and markers related to LTS tolerance at germination and early growth stages in rice that can be used to facilitate marker-assisted breeding through recurrent selection.

\section{Materials and methods}

Plant materials

The experiment was conducted at the International Rice Research Institute (IRRI), Los Baños, Philippines (14 ${ }^{\circ}$ $\left.11 \mathrm{~N}, 121^{\circ} 15 \mathrm{E}\right)$ during 2015 using an early backcross mapping population of $230 \mathrm{BC}_{1} \mathrm{~F}_{7}$ lines developed by single backcross with recipient parent WTR-1 and HNG as the pollen (donor) parent. The population was developed by using single seed descent method at IRRI, and further detailed information of this breeding scheme and population development were explained in Jewel et al. (2019) and Murugaiyan et al. (2019). Both parents showed $100 \%$ germination rate under control conditions $\left(27^{\circ} \mathrm{C}\right.$ and $19^{\circ} \mathrm{C}$ day/night temperature), whereas, at LT $\left(14{ }^{\circ} \mathrm{C} / 12{ }^{\circ} \mathrm{C}\right)$, the former showed a low germination rate and the latter a high germination rate.

Phenotypic evaluation of early germination and seedling vigor traits under LTS

One hundred seeds of each line were placed on a double paper towel in 9-cm Petri dishes moistened with double distilled water in a complete randomized design (CRD) with two replications each. To eliminate the effect of dormancy on seed germination, the seed samples were incubated at $50{ }^{\circ} \mathrm{C}$ for 1 week before conducting the experiment. The materials were put inside the indoor growth chamber at IRRI adjusted to $14{ }^{\circ} \mathrm{C}$ and $12{ }^{\circ} \mathrm{C}$ day and night temperature, respectively, with relative humidity fixed at $70 \%$. The light intensity was adjusted at 450 micro mol quanta $\mathrm{m}^{-2} \mathrm{~s}^{-5}$ (normal daynight cycle) was used. Six $1000 \mathrm{~W}$ incandescent bulbs were placed inside the chamber at approximately $50 \mathrm{~cm}$ above the chamber floor and were adjusted to provide a 13-h light period and 11-h dark period. The moisture level in the Petri plates was routinely checked every day after placing the seed inside the controlled chamber. The control treatment was laid out in the same manner inside the Phytotron facilities provided at IRRI, except for the temperature conditions, which were fixed at the normal range, $27^{\circ} \mathrm{C}$ and $19^{\circ} \mathrm{C}$ for day and night temperature, respectively. Data were recorded on five traits: lowtemperature germination percentage (LTG) (\%), shoot length (SL) (mm), root length (RL) (mm), biomass weight (BW) (g), and seedling vigor index (SVI). All traits except BW were recorded in three stages, LTG at 2, 4, and 6 days after sowing (DAS), whereas SL, RL, and SVI were noted at 10, 13, and 16 days after incubation. However, BW was recorded in the last stage only, which was on day 16 of incubation (Table 1).

Germination was defined as the emergence of a radical or plumule of $\geq 1 \mathrm{~mm}$ as proposed by Counce et al. (2000). Germination percentage (GP) at LT was 
Table 1 Traits' observations related to seed germination and early seedling vigor traits in rice

\begin{tabular}{|c|c|c|c|}
\hline $\begin{array}{l}\text { S. } \\
\text { no. }\end{array}$ & $\begin{array}{l}\text { Trait } \\
\text { designation }\end{array}$ & Stages & Trait description \\
\hline 1 & LTG & LTG-I, LTG-II, and LTG-III & $\begin{array}{l}\text { The numbers of seeds germinated after } 2,4 \text {, and } 6 \text { days of sowing were } \\
\text { calculated as germination percentage (GP) at low temperature (day/night } \\
\text { temperature is } 14^{\circ} \mathrm{C} / 12^{\circ} \mathrm{C} \text { ). }\end{array}$ \\
\hline 2 & SL & SL-I, SL-II, and SL-III & $\begin{array}{l}\text { Measured from the collar region to the tip of the topmost leaf at stages of } 10 \text {, } \\
13 \text {, and } 16 \text { days after incubation at low temperature }\end{array}$ \\
\hline 3 & RL & RL-I, RL-II, and RL-III & $\begin{array}{l}\text { Measured from the collar region down to the tip of the longest root at stages } \\
\text { of } 10,13 \text {, and } 16 \text { days after incubation at low temperature. }\end{array}$ \\
\hline 4 & SVI & SVI-I, SV-II, and SVI-III & $\begin{array}{l}\text { Seedling vigor index were calculated in } 10,12 \text {, and } 16 \text { days of sowing by } \\
\text { using with formula as SVI }=[\mathrm{GP} \times \text { shoot length }(\mathrm{mm})] / 100\end{array}$ \\
\hline 5 & BW & BW-III & $\begin{array}{l}\text { Fresh biomass recorded in only last stage which was on the 16th day of } \\
\text { incubation }\end{array}$ \\
\hline 4 & LTGS & LTGS-I, LTGS-II, and LTGS-III, & $\begin{array}{l}\text { Stress index }(\mathrm{SI}) \text { of } \mathrm{LTG} \text { trait were calculated using the following formula as } \\
\mathrm{SI}=(\mathrm{OSC}-\mathrm{ONC}) / \mathrm{ONC} \text { where OSC = phenotypic observation under } \\
\text { stress conditions; ONC = phenotypic observation under normal condi- } \\
\text { tions. }\end{array}$ \\
\hline 5 & RLSI & RLSI-I, RLSI-II, and RLSI-III & $\begin{array}{l}\text { Stress index }(\mathrm{SI}) \text { of } \mathrm{RL} \text { were calculated using the following formula as } \\
\mathrm{SI}=(\mathrm{OSC}-\mathrm{ONC}) / \mathrm{ONC} \text {. }\end{array}$ \\
\hline 6 & SLSI & SLSI-I, SLSI-II, and SLSI-III & $\begin{array}{l}\text { Stress index }(\mathrm{SI}) \text { of SL were calculated using the following formula as } \\
\quad \mathrm{SI}=[(\mathrm{OSC}-\mathrm{ONC}) / \mathrm{ONC}]\end{array}$ \\
\hline 7 & AGP & AGP-I, AGP-II, and AGP-III & $\begin{array}{l}\text { Adjusted germination percent }(\mathrm{AGP})=(\text { germination percent under stress } \\
\text { condition divided by germination under normal condition }) \times 100\end{array}$ \\
\hline 8 & BMSI & BMSI-III & Calculated biomass stress index at 16 th days after sowing \\
\hline 9 & $\begin{array}{l}\text { RGP, SGI, } \\
\text { and RGI }\end{array}$ & $\begin{array}{l}\text { RGP (I-II), RGP (II-III), SGI (I-II), SGI } \\
\quad \text { (II-III), RGI (I-II), and RGI (II-III) }\end{array}$ & $\begin{array}{l}\text { The relative germination percentage (RGP), shoot growth index (SGI), and } \\
\text { root growth index (RGI) were calculated based on the increased growth } \\
\text { from stage I to II, and stage II to III used in the data observations. }\end{array}$ \\
\hline
\end{tabular}

calculated as $(\mathrm{LTG})=(\mathrm{GN} / \mathrm{NG}) \times 100$, where $\mathrm{GN}=$ number of germinated seeds and $\mathrm{NG}=$ total number of grains (Wang et al. 2010). In a similar way, stress tolerance index (SI) for low temperature germination (LTGS), shoot length (SLSI), root length (RLSI), and biomass (BMSI) was calculated according to the formula $\mathrm{SI}=(\mathrm{OSC}-\mathrm{ONC}) / \mathrm{ONC}$, where OSC is the phenotypic observation under stress conditions and $\mathrm{ONC}$ is the phenotypic observation under normal conditions (Cruz and Milach 2004; Bosetti et al. 2012; Zhang et al. 2014a). Values toward zero indicate a lower stress index of a genotype, which means tolerance of LTS, whereas -1 value indicates no tolerance at all. Furthermore, adjusted germination percentage was calculated as $(\mathrm{AGP})=($ Germination percentage under stress conditions divided by germination under normal conditions) $\times 100$ (Shakiba et al. 2017). The seedling vigor index (SVI) was calculated by using the formula SVI $=$ LTG $\times$ SL $(\mathrm{mm}) / 100$ (Abdul-Baki and Anderson 1973). Similarly, we focused on the relative germination percentage (RGP), shoot growth index (SGI), and root growth index (RGI) that were calculated, based on the increasing the germination rate, shoot and root growth from stage I to II, and stage II to III used in the data observations. The phenotypic data of the traits were analyzed using statistical software "Plant Breeding Tools" version 1.4 (http://bbi.irri.org/products) for descriptive statistics, including mean, standard deviation, minimum and maximum values, coefficient of variation (\%), skewness, kurtosis, and the difference between individuals within ILs. Further, mean data over replications for all traits were used for QTL IciMapping (Meng et al. 2015).

\section{Genotyping and filtering of 6 K SNP data}

Fresh young leaves of 230 ILs and parents were collected after 16 DAS. A modified CTAB method was used for DNA extraction (Murray and Thompson 1980), which was quantified by a NanoDrop 8000 spectrophotometer (Thermo Scientific, USA). For the SNP array, DNA concentrations were adjusted at approximately 
$50 \mathrm{ng} / \mu \mathrm{l}$, and further processing was done according to the manufacturer's instructions for the Illumina Infinium assay using a $6 \mathrm{~K}$ gene chip in the Genotyping Services Laboratory of IRRI. The resulting intensity data were processed by using genotyping module V2011.1 of Genome Studio software (Illumina Inc., San Diego, CA, USA) for SNP calling. The genotypic data were filtered based on the polymorphic markers between the parents, and we further removed the heterozygous and monomorphic alleles in the parents by filtering using Microsoft Excel.

\section{QTL mapping}

The high quality of 704 SNP markers was distributed on all 12 chromosomes. The degree of polymorphism in each chromosome was calculated based on the number of polymorphic SNPs distributed in the chromosome, divided by the total number of SNP markers. The linkage between SNP marker and traits analysis was performed by using IciMapping4.0 (Meng et al. 2015). Mean values of each phenotypic data point were used as input to detect QTLs by the single marker analysis (SMA) method. The logarithm of odds (LOD) threshold value was obtained based on the permutation test $(n=$ $1000 ; P=0.05$ ) of each trait for claiming the significant QTLs with a LOD score of $\geq 3.0$. The additive effect with a positive value indicated that the desirable allele came from the recurrent parent (WTR-1), whereas a negative additive value showed that the desirable allele was received from the donor parent (HNG). Autofiltration of QTLs concerned with different phenotypic traits was done using Microsoft Excel 2007.

\section{Results}

Germination and seedling growth parameters

The phenotypic variance analysis detected a significant difference in the ILs under LTS and ambient temperature (control) conditions. For the variance between the parents, HNG showed a higher value for LTG, SL, RL, and SVI in all three stages, except at 16 DAS-RL. The results of descriptive statistics of LTG ranges were 0$60 \%, 0.5-95 \%$, and $0-98 \%$ at 2 (LTG-I), 4 (LTG-II), and 6 DAS (LTG-III), whereas $-6.0-89 \%$ was recorded for RGP (I-II), 0-60\% for RGP (II-III), and 0-101.8\% for AGP-I, $0-171.8 \%$ for AGP-II, and $0-125.4 \%$ for
AGP-III in all three stages. Similarly, a wide range in variance was observed for SL (I, 0-20.5 cm; II, 0$33.5 \mathrm{~cm}$; and III, 0-45.6 cm), RL (I, 0-20.9 cm; II, 0$31.5 \mathrm{~cm}$; and III, 0-41.2 cm), and SVI (I, 0-15.6; II, 045.8; and III, 0-76.6) at 10, 13, and 16 DAS, respectively (Table 2). The germination rate for all three stages was quite distinct in WTR-1 $(8.5 \%, 43 \%$, and $76 \%)$ and HNG $(13.5 \%, 48.5 \%$, and $81.5 \%)$ and the high mean germination indicates higher LTS tolerance in the donor parent. As compared to the parents, $19.5 \%, 34 \%$, and $33 \%$ of the ILs recorded higher LTG at 2, 4, and 6 DAS, respectively, whereas some of them were more sensitive to cold stress than WTR-1 due to lower GP, indicating that ILs followed transgressive segregation (Table 2). On the other hand, 24 ILs constituting $10.4 \%$ of the total genotypes showed a significantly higher germination rate under cold stress in all the stages (Fig. 1 and Table 3). Of the 24 ILs, five promising lines were identified, G-1-Y7-NU4-3-5-7, G-1-Y7-NU2-1-3-14, G-1-Y7-NU4-3-5-6, G-1-RF6-NU3-4-7-40, and G-IY7-NU4-3-5-7, which showed more than $95 \%$ germination under LTS. Moreover, a broad range of variation was observed in ILs for LTG, SL, RL, and SVI, which indicates the scope for the selection of superior genotypes with cold tolerance. Similarly, Fig. 2 represents $7.5 \%$ of the ILs (18 lines) showing less than $<0.5$ overall mean stress index.

Of all the LTS tolerance traits studied in the present experiment in three different stages, LTG-III, 13 DASSL, 13 DAS-RL, 16 DAS-SL, and 16 DAS-RL were found to be negatively skewed, while the remaining were observed to be positively skewed under cold stress (Table 2). The kurtosis values were negative and varied from -0.59 to -1.66 for 10 DAS-SL and 16 DAS-SL, respectively. Therefore, the shape of the distributions was classified as platykurtic in cold stress as it was less peaky than the Gaussian distribution. All the traits except LTG at stages I and II and SVI followed a normal distribution pattern. The results of ANOVA (analysis of variance) for tolerance traits under LTS conditions are shown in Table 4 and the combination of different growth stages in cold conditions is given in Supplemental Table 1. Among all the traits studied, the largest coefficient of variation (CV) was measured in SGI (II-III) (24.4\%), followed by RGI (II-III) (22.3\%) and RGII (I-II) (18.7\%), and SVI-I (18.0\%). A highly significant difference was detected among genotypes and conditions for all the traits. The $\mathrm{CV}$ range for five basic traits was observed from $3.21 \%$ for RL-III to 
Table 2 Comparison of LTS tolerance indicators (phenotypic traits) of the parents and ILs under cold and normal conditions

\begin{tabular}{|c|c|c|c|c|c|c|c|c|}
\hline S. no. & Cold tolerance indicator & Condition & $\begin{array}{l}\text { Mean } \\
\text { WTR-1 }\end{array}$ & $\begin{array}{l}\text { Mean } \\
\text { HNG }\end{array}$ & $\begin{array}{l}\text { Mean } \pm \text { S.D. } \\
\text { IL population }\end{array}$ & Range & Skewness & Kurtosis \\
\hline \multirow[t]{2}{*}{1} & \multirow[t]{2}{*}{ LTG-I } & $\mathrm{NC}$ & 41.00 & 97.50 & $40.80 \pm 23.10$ & $3-100$ & 0.37 & -0.68 \\
\hline & & $\mathrm{SC}$ & 8.50 & 13.80 & $7.20 \pm 11.10$ & $0-60$ & 2.07 & 4.90 \\
\hline \multirow[t]{2}{*}{2} & \multirow[t]{2}{*}{ LTG-II } & $\mathrm{NC}$ & 89.00 & 100.00 & $77.20 \pm 20.90$ & $3-100$ & -1.77 & 2.82 \\
\hline & & $\mathrm{SC}$ & 30.60 & 48.60 & $44.01 \pm 23.50$ & $0-95$ & 0.43 & -0.87 \\
\hline \multirow[t]{2}{*}{3} & \multirow[t]{2}{*}{ LTG-III } & $\mathrm{NC}$ & 89.00 & 100.00 & $77.20 \pm 20.90$ & $3-100$ & -1.77 & 2.82 \\
\hline & & $\mathrm{SC}$ & 56.70 & 81.20 & $60.30 \pm 27.80$ & $0-98$ & -0.63 & -1.34 \\
\hline \multirow[t]{2}{*}{4} & \multirow[t]{2}{*}{ RL-I } & $\mathrm{NC}$ & 49.10 & 29.60 & $41.80 \pm 14.80$ & $0-87.6$ & -0.25 & 0.71 \\
\hline & & $\mathrm{SC}$ & 5.40 & 12.30 & $6.90 \pm 5.80$ & $0-20.9$ & 0.02 & -1.33 \\
\hline \multirow[t]{2}{*}{5} & \multirow[t]{2}{*}{ RL-II } & $\mathrm{NC}$ & 53.90 & 47.40 & $58.00 \pm 17.20$ & $0-92.2$ & -0.99 & 2.63 \\
\hline & & $\mathrm{SC}$ & 22.00 & 16.40 & $12.40 \pm 10.00$ & $0-31.5$ & -0.19 & -1.49 \\
\hline \multirow[t]{2}{*}{6} & \multirow[t]{2}{*}{ RL-III } & $\mathrm{NC}$ & 54.70 & 62.30 & $31.40 \pm 35.00$ & $0-95.8$ & 0.34 & -1.65 \\
\hline & & $\mathrm{SC}$ & 28.70 & 27.10 & $16.40 \pm 13.60$ & $0-41.2$ & -0.23 & -1.63 \\
\hline \multirow[t]{2}{*}{7} & \multirow[t]{2}{*}{ SL-I } & $\mathrm{NC}$ & 17.60 & 20.00 & $27.60 \pm 7.80$ & $0-42.5$ & -1.11 & 1.81 \\
\hline & & $\mathrm{SC}$ & 7.20 & 11.70 & $5.60 \pm 5.00$ & $0-20.5$ & 0.40 & -0.59 \\
\hline \multirow[t]{2}{*}{8} & \multirow[t]{2}{*}{ SL-II } & $\mathrm{NC}$ & 54.00 & 42.00 & $55.10 \pm 12.60$ & $0-76.4$ & -2.71 & 9.74 \\
\hline & & $\mathrm{SC}$ & 23.00 & 24.20 & $12.70 \pm 10.10$ & $0-33.5$ & -0.24 & -1.49 \\
\hline \multirow[t]{2}{*}{9} & \multirow[t]{2}{*}{ SL-III } & $\mathrm{NC}$ & 55.20 & 46.20 & $30.50 \pm 33.10$ & $0-82.3$ & 0.20 & -1.89 \\
\hline & & $\mathrm{SC}$ & 28.20 & 30.00 & $17.90 \pm 14.80$ & $0-45.6$ & -0.23 & -1.66 \\
\hline \multirow[t]{2}{*}{10} & \multirow[t]{2}{*}{ SVI-I } & $\mathrm{NC}$ & 27.30 & 48.30 & $33.98 \pm 21.20$ & $0-89.7$ & 0.56 & -0.43 \\
\hline & & $\mathrm{SC}$ & 0.80 & 4.80 & $1.24 \pm 2.50$ & $0-15.6$ & 2.46 & 8.05 \\
\hline \multirow[t]{2}{*}{11} & \multirow[t]{2}{*}{ SVI-II } & $\mathrm{NC}$ & 96.00 & 89.40 & $88.40 \pm 30.70$ & $0-150.9$ & -1.07 & 1.31 \\
\hline & & $\mathrm{SC}$ & 33.70 & 37.40 & $13.10 \pm 12.40$ & $0-45.8$ & 0.48 & -0.92 \\
\hline \multirow[t]{2}{*}{12} & \multirow[t]{2}{*}{ SVI-III } & $\mathrm{NC}$ & 97.70 & 108.40 & $49.30 \pm 56.00$ & $0-162.3$ & 0.40 & -1.59 \\
\hline & & $\mathrm{SC}$ & 52.80 & 54.50 & $25.10 \pm 22.80$ & $0-76.6$ & 0.09 & -1.61 \\
\hline \multirow[t]{2}{*}{13} & \multirow[t]{2}{*}{ BW-III } & $\mathrm{NC}$ & 0.50 & 0.50 & $0.67 \pm 0.30$ & $0-1.53$ & -0.28 & 0.77 \\
\hline & & $\mathrm{SC}$ & 0.20 & 0.12 & $0.14 \pm 0.12$ & $0-0.6$ & 0.29 & -0.62 \\
\hline 14 & AGP-I & - & 16.85 & 20.35 & $13.86 \pm 21.09$ & $0-101.80$ & 16.95 & 16.4 \\
\hline 15 & AGP-II & - & 86.65 & 91.90 & $57.53 \pm 26.59$ & $0-171.40$ & 3.67 & -1.17 \\
\hline 16 & AGP-III & - & 98.00 & 95.95 & $73.74 \pm 27.99$ & $0-125.40$ & -5.44 & -4.69 \\
\hline 17 & SGI (I-II) & - & -0.80 & -0.80 & $-0.86 \pm 0.21$ & $-1-0.10$ & 17.43 & 18.08 \\
\hline 18 & SGI (II-III) & - & -0.15 & -0.10 & $-0.41 \pm 0.31$ & $-1-0.80$ & 8.18 & 5.03 \\
\hline 19 & SGI (I-III) & - & 0.00 & 0.00 & $-0.15 \pm 0.59$ & $-1-50$ & 33.11 & 107.79 \\
\hline 20 & RGP (I-II) & - & 40.50 & 54.50 & $36.98 \pm 19.69$ & $-6-89$ & 3.4 & -2 \\
\hline 21 & RGP (II-III) & - & 37.00 & 18.00 & $16.27 \pm 15.44$ & $0-60$ & 8.77 & -0.25 \\
\hline 22 & RGI (I-II) & - & 10.55 & 7.00 & $5.4 \pm 5.67$ & $-3.70-23.90$ & 6.77 & -0.51 \\
\hline 23 & RGI (II-III) & - & 7.75 & 10.55 & $3.97 \pm 6.16$ & $-29.80-25.80$ & -6.78 & 23.7 \\
\hline
\end{tabular}

$D A S$ days after sowing, $N C$ normal (or ambient) conditions, $S C$ stress condition. Cold tolerance trait abbreviations were given in Table 1

$24.45 \%$ for SGI (II-III). The correlation coefficient was performed initially, using the main traits like LTG, SL, RL, BW, and SVI which were calculated for three stages. Further, the correlation indices of these traits like LTGS, SLSI, RLSI, and BMSI were calculated separately for all three stages. Among these, the correlation coefficients of LTG with BM, RL, SL, and SVI were high and significant (Table 5). Similarly, BM under cold stress demonstrated a strong association with RL, SL, and SVI. Moreover, RL showed a significant and 


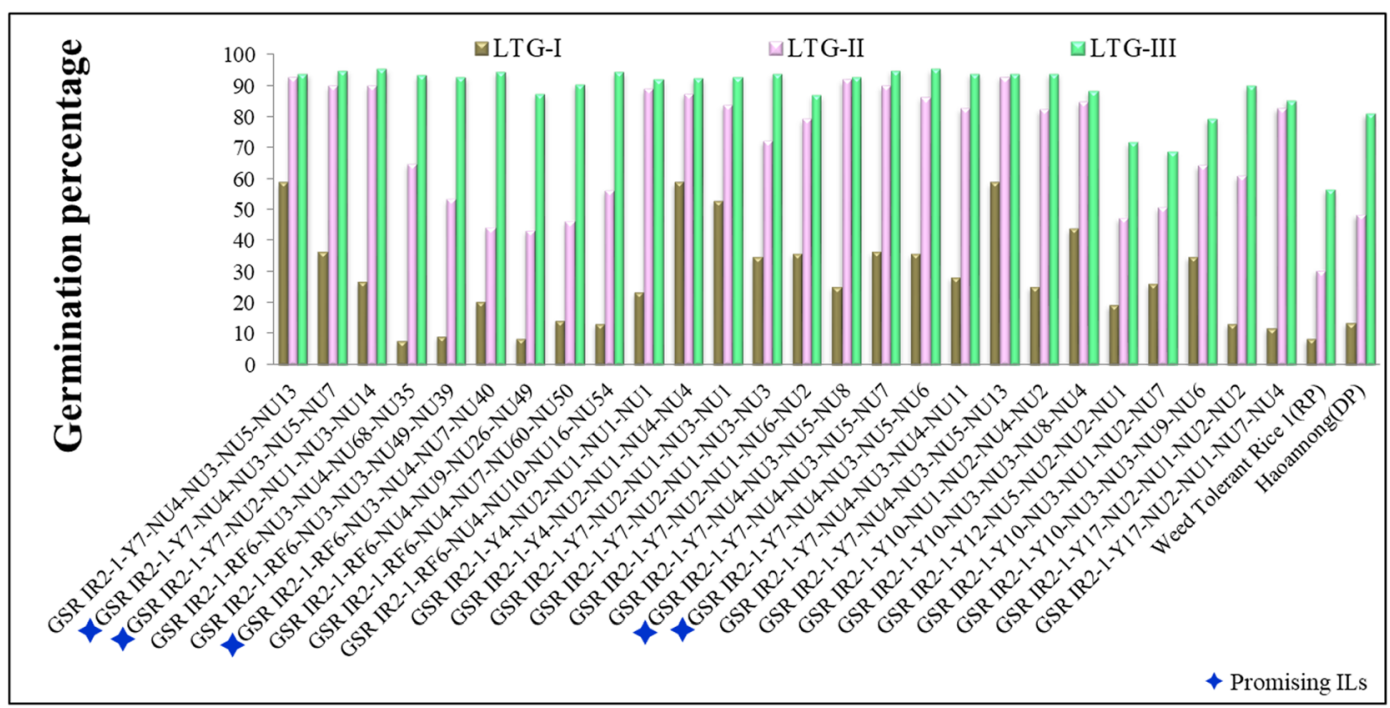

Fig. 1 Graphical depiction of 24 promising BILs ( $12 \%$ of the total BIL population) identified for LTS tolerance

high association with SL $(r=0.93)$, and SVI $(r=0.88)$ in LTG-III and a similar trend was observed between SL and SVI $(r=0.90)$ in LTG-III. On the other hand, nonsignificant correlations were observed among stress indices, except for the very high and positive association between RLSI and SLSI. The strength of most of the correlations increased markedly toward the later stages. This kind of observation to some extent could be explained by the QTL linkage mapping results, wherein some genomic regions were occupied by QTLs associated with most of these traits under LT conditions.

\section{QTLs for LTS tolerance traits}

The linkage map was constructed by using 704 highquality SNP polymorphic markers, distributed on a total genome size of 353.5 million bases (Mb). The level of polymorphism varied between chromosomes, ranging from $6.1 \%$ (chromosome 8 ) to $11.9 \%$ (chromosome 4), and the length of the chromosomes ranged from 19.5 $\mathrm{Mb}$ (chromosome 10) to $42.3 \mathrm{Mb}$ (chromosome
1) (Fig. 3). To concentrate on more significant QTLs contributing maximum phenotypic variation (PV) for germination and early seedling growth traits, the critical LOD threshold was set at $\geq 3.0$, which is higher than the level used in many other studies, and this also reduced the false positives. A total of 82 QTLs were mapped on the 12 chromosomes associated with 16 LTS tolerance traits in three different growth stages (Table 6). These traits were LTG-I, II, and III; LTGS-I, II, and III; RLSI-I and RLSI-II; BMSI and SVI-I, II, and III; SLSI-I; SL-II; RL-I; and SGI, and they explained PV ranging from 6.95 to $23.38 \%$. The number of QTLs associated with phenotypic traits ranged from one to nine, and these are depicted in Figs. 4 and 5 and listed in Table 6. An average of 6.8 QTLs are distributed on each chromosome, and the highest number of QTLs was found to be located on chromosome 11, containing 15 QTLs, and chromosomes 6 and 1 each had nine QTLs, together explaining average PV of $8.40 \%, 10.19 \%$, and $10.03 \%$, respectively (Fig. 4). In total, about $67 \%$ of the desirable alleles for QTLs were received from the donor parent

Table 3 Mean performances of 24 ILs identified for high germination rate and low-stress index value under low-temperature stress conditions

\begin{tabular}{lllllll}
\hline S. no. & Type of population & \multicolumn{2}{l}{ Mean \pm SD } & & \multirow{2}{*}{ Mean stress index } \\
\cline { 3 - 5 } & & \multicolumn{1}{l}{ LTG-I } & LTG-II & LTG-III & All traits \\
\hline 1 & Promising ILs & $29.50 \pm 14.90$ & $73.50 \pm 16.70$ & $89.80 \pm 6.70$ & -0.27 \\
2 & Entire IL population & $7.20 \pm 11.10$ & $44.00 \pm 23.50$ & $60.30 \pm 27.80$ & -0.58 \\
\hline
\end{tabular}




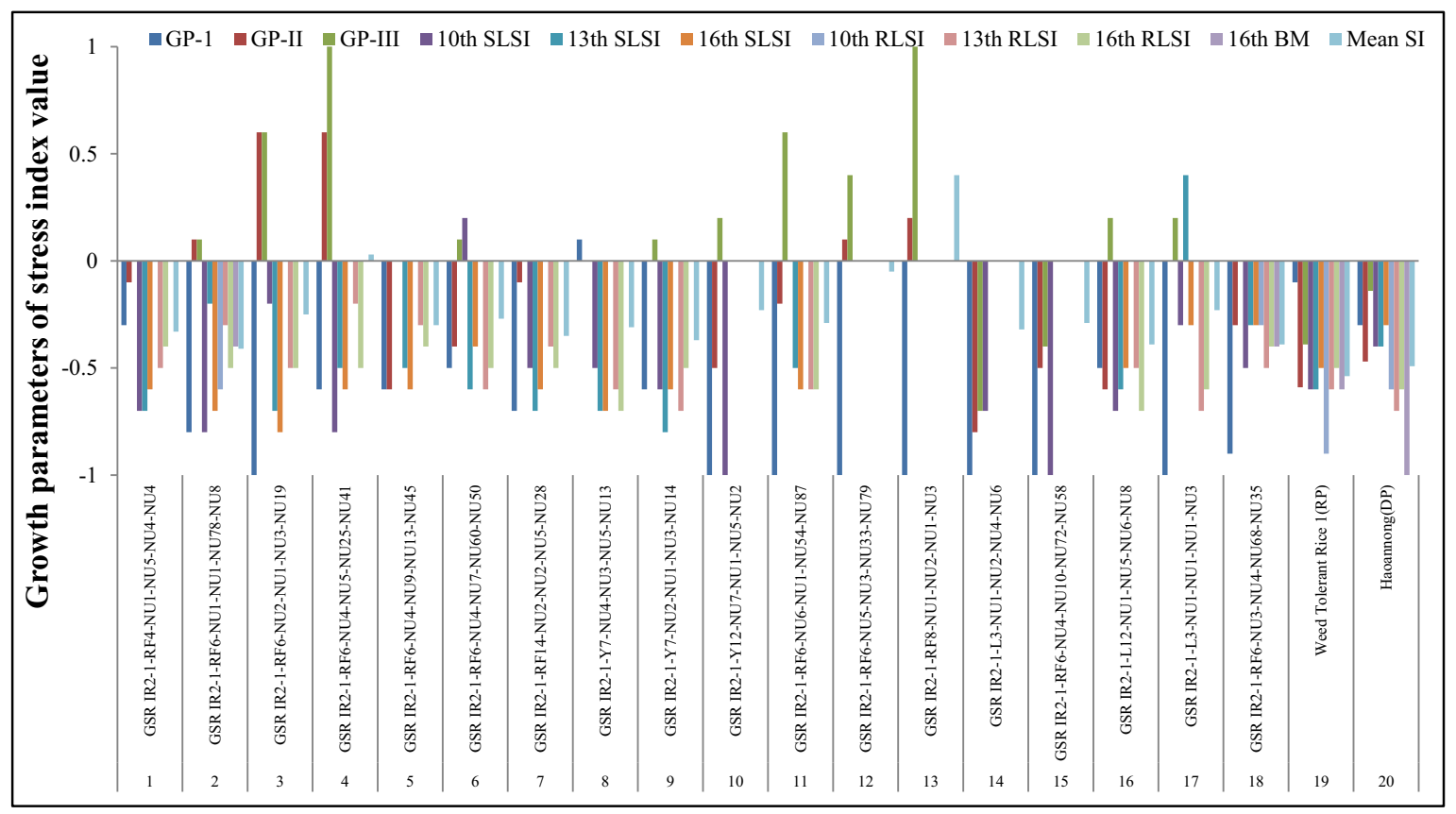

Fig. 2 Graphical depiction of 18 promising ILs ( $7.5 \%$ of the total ILs) by low-stress index for all the traits in different growth stages with mean values

(HNG), whereas the recipient parent contributed $33 \%$ of the favorable alleles. The contribution of M-QTLs regarding PV explained ranged from 10 to $23.38 \%$, and five significant M-QTLs were considered to be major QTLs since the PV explained surpassed $15 \%$. The highest PV explained of $16.57 \%\left(q L T G S(I-I I)_{1}\right)$,
$16.08 \%\left(q L T G(I)_{1}\right), 23.38 \%\left(q L T G S(I)_{5}\right), 18.56 \%$ $\left(q L T G(I)_{5}\right)$, and $20.12 \%\left(q L T G(I)_{7}\right)$ was located at $41.04 \mathrm{Mb}$ and $42.4 \mathrm{Mb}$ on chromosome 1 , at $28.6 \mathrm{Mb}$ on chromosome 5 , and at $3.85 \mathrm{Mb}$ on chromosome 7 , respectively, and exhibited a mean LOD score of 8.77 (Table 6).

Table 4 Analysis of variance for LTS tolerance traits in three different growth stages in rice

\begin{tabular}{|c|c|c|c|c|c|c|c|}
\hline \multirow[t]{2}{*}{ S. no. } & \multirow[t]{2}{*}{ Source of variation } & \multirow[t]{2}{*}{ DF } & \multicolumn{5}{|c|}{ Mean squares (variances) } \\
\hline & & & LTG & SL & RL & SVI & BW \\
\hline 1 & Genotypes & 230 & $\begin{array}{l}3325.1 \\
\operatorname{Pr}(<0.01)\end{array}$ & $\begin{array}{l}879.2 \\
\operatorname{Pr}(<0.01)\end{array}$ & $\begin{array}{l}1194.6 \\
\operatorname{Pr}(<0.01)\end{array}$ & $\begin{array}{l}3140.7 \\
\operatorname{Pr}(<0.01)\end{array}$ & 0.1 \\
\hline 2 & Conditions (normal/stress) & 1 & $\begin{array}{l}611,371.4 \\
\operatorname{Pr}(<0.01)\end{array}$ & $\begin{array}{l}452,520.4 \\
\operatorname{Pr}(<0.01)\end{array}$ & $\begin{array}{l}698,899.5 \\
\operatorname{Pr}(<0.01)\end{array}$ & $\begin{array}{l}1,344,434.8 \\
\operatorname{Pr}(<0.01)\end{array}$ & $\begin{array}{l}32.03 \\
\operatorname{Pr}(<0.01)\end{array}$ \\
\hline 3 & Stages (I, II, III) & 2 & $\begin{array}{l}462,681.2 \\
\operatorname{Pr}(<0.01)\end{array}$ & $\begin{array}{l}69,864.1 \\
\operatorname{Pr}(<0.01)\end{array}$ & $\begin{array}{l}37,737.4 \\
\operatorname{Pr}(<0.01)\end{array}$ & $\begin{array}{l}258,367.8 \\
\operatorname{Pr}(<0.01)\end{array}$ & - \\
\hline 4 & Genotype: condition & 230 & $\begin{array}{l}1131.9 \\
\operatorname{Pr}(<0.01)\end{array}$ & $\begin{array}{l}742.9 \\
\operatorname{Pr}(<0.01)\end{array}$ & $\begin{array}{l}1044.9 \\
\operatorname{Pr}(<0.01)\end{array}$ & $\begin{array}{l}2262.9 \\
\operatorname{Pr}(<0.01)\end{array}$ & $\begin{array}{l}0.05 \\
\operatorname{Pr}(<0.01)\end{array}$ \\
\hline 5 & Genotype: stage & 460 & $\begin{array}{l}353.3 \\
\operatorname{Pr}(<0.01)\end{array}$ & $\begin{array}{l}428.4 \\
\operatorname{Pr}(<0.01)\end{array}$ & $\begin{array}{l}464.2 \\
\operatorname{Pr}(<0.01)\end{array}$ & $\begin{array}{l}1260.6 \\
\operatorname{Pr}(<0.01)\end{array}$ & - \\
\hline 6 & Condition: stage & 2 & $\begin{array}{l}32,215.6 \\
\operatorname{Pr}(<0.01)\end{array}$ & $\begin{array}{l}53,153.0 \\
\operatorname{Pr}(<0.01)\end{array}$ & $\begin{array}{l}29,551.5 \\
\operatorname{Pr}(<0.01)\end{array}$ & $\begin{array}{l}172,965.6 \\
\operatorname{Pr}(<0.01)\end{array}$ & - \\
\hline 7 & Genotype: condition: stage & 460 & $\begin{array}{l}296.4 \\
\operatorname{Pr}(<0.01)\end{array}$ & $\begin{array}{l}418.1 \\
\operatorname{Pr}(<0.01)\end{array}$ & $\begin{array}{l}460.5 \\
\operatorname{Pr}(<0.01)\end{array}$ & $\begin{array}{l}1227.3 \\
\operatorname{Pr}(<0.01)\end{array}$ & - \\
\hline 8 & Error & 1392 & 5.4 & 1.8 & 1.8 & 6.3 & 0.004 \\
\hline 9 & $\mathrm{CV}(\%)$ & & 4.48 & 18.43 & 14.93 & 7.14 & 16.39 \\
\hline
\end{tabular}


Table 5 Correlation analysis of the different traits used as cold tolerance phenotypes

\begin{tabular}{llllll}
\hline & LTG & BM & RL & SL & SVI \\
\hline LTG & 1.000 & $0.19,\left(0.41^{*}\right),\left[0.51^{* *}\right]$ & n.s., $\left(0.41^{*}\right),\left[0.55^{* *}\right]$ & n.s, $\left(0.44^{*}\right),\left[0.58^{* *}\right]$ & $0.79,\left(0.75^{* *}\right),\left[0.76^{* *}\right]$ \\
BM & & 1.000 & $0.80^{* *},\left(0.80^{* *}\right),\left[0.81^{* *}\right]$ & $0.78,\left(0.84^{* *}\right),\left[0.84^{* *}\right]$ & $0.42^{*},\left(0.72^{* *}\right),\left[0.76^{* *}\right]$ \\
RL & & & 1.000 & $0.88^{* *},\left(0.91^{* *}\right),\left[0.93^{* *}\right]$ & $\left.0.53^{* *}\right),\left(0.81^{* *}\right),\left[0.88^{* *}\right]$ \\
SL & & & 1.000 & $0.63^{* *},\left(0.83^{* *}\right),\left[0.90^{* *}\right]$ \\
SVI & & & & & 1.000 \\
& LTGS & BMSI & RLSI & SLSI & \\
LTGS & 1.000 & n.s. & n.s, (n.s), [n.s $]$ & n.s (n.s. $),[$ n.s. $]$ & \\
BMSI & & n.s. & n.s & $0.83^{* *},\left(0.87^{* *}\right),[0.97 * *]$ \\
RLSI & & & 1.000 & 1.000 & \\
SLSI & & & & 1.000 & \\
\hline
\end{tabular}

Trait measurements and abbreviations are expanded in Table 1 (Values without brackets represent correlation coefficients for stage I; values inside short brackets for stage II; values inside long brackets for stage III)

QTLs for LTS germination and stress index at three stages

A total of 21 and 26 QTLs associated with LTG and LTGS. These QTLs were located on all the chromosomes, except for chromosomes 12 (Table 6). Out of these QTLs, nine were found to be involved in LTG-I and six QTLs each for LTG-II and -III, whereas in LTGS, 13 QTLs for LTGS-I, four QTLs for LTGS-II, and nine QTLs for LTGS-III, respectively. Among them, the highest PV was explained by five QTLs $\left(q L T G(I)_{1}, q L T G S(I)_{1-2}, q L T G(I)_{5}, q L T G S(I)_{5}\right.$, and $\left.q L T G(I)_{7}\right)$, on chromosomes 1,5 , and 7 , respectively and both of these QTLs received desirable alleles from the donor parent (Table 6). Interestingly, the genomic segments at $28.6 \mathrm{Mb}$ and $3.85 \mathrm{Mb}$ on chromosomes 5 and 7 were shared by germination stage II QTLs $\left(q L T G(I I)_{5}\right.$ and $\left.q L T G(I I)_{7}\right)$, whereas the chromosome segments occupied by $q L T G(I I)_{11}$, a stage II QTL on chromosome 11, were found to overlap with $q L T G(I I I)_{11}$, a stage III QTL. However, the majority of the favorable alleles of such QTLs were contributed by HNG.

In total, nine QTLs each for RLSI and BMSI, seven QTLs for SVI, five QTLs for SGI, three QTLs for SLSI, and a single QTL each for RL and SL, and these QTLs explained PV ranging from 6.95 to $23.38 \%$ (Figs. 4 and 5). Among them, 22 minor QTLs with PVE ranging from $6.95 \%\left(q R L S I(I I)_{6}\right)$ to $9.37 \%\left(q B M S I(I I)_{2}\right)$, whereas five of them are major-effect QTLs explained the PV more than $10 \%$ (Table 6). These major QTLs $(q R L S I(I))_{2}$, $q R L S I(I)_{3}, q R L S I(I)_{6}, q R L S I(I)_{9}$, and $\left.q R L S I(I)_{11}\right)$ were
Fig. 3 Genomic distribution and genome coverage of polymorphic SNP markers

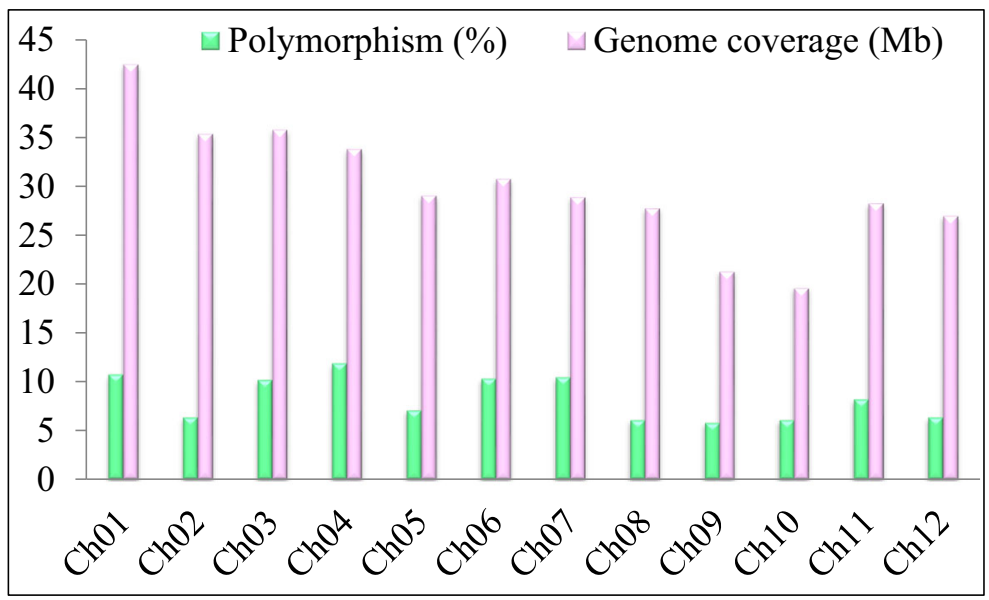




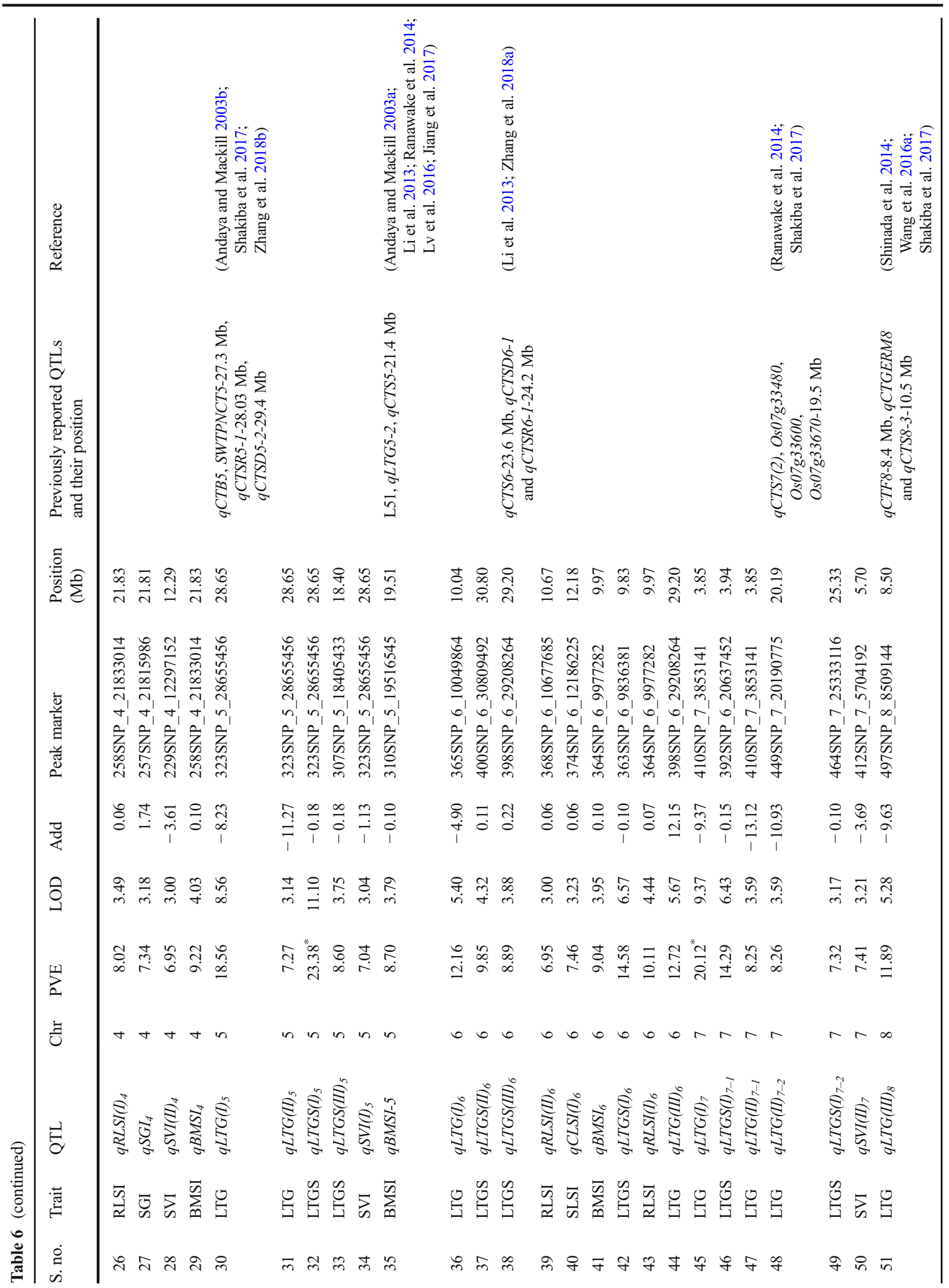




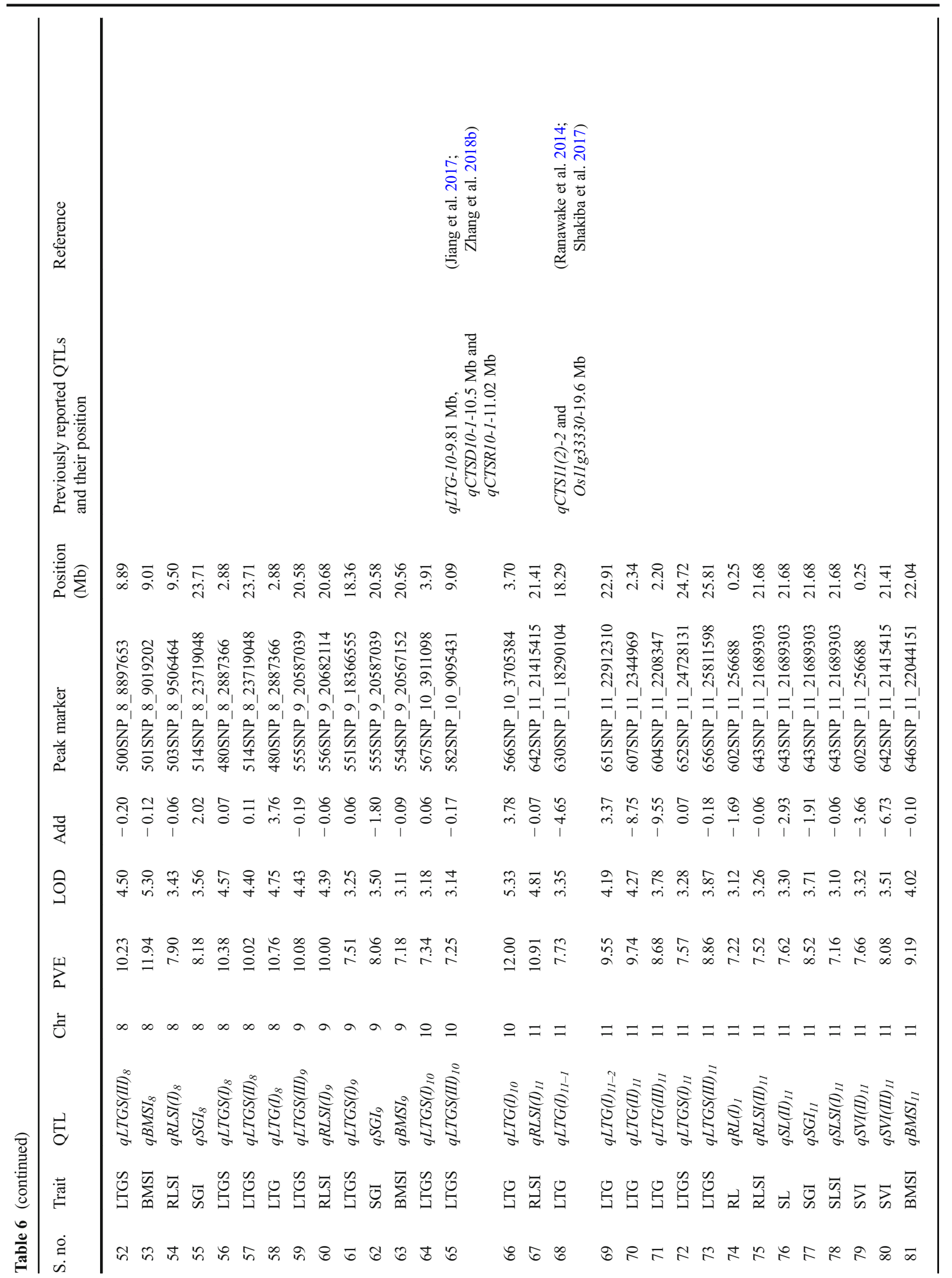


located on specific genomic regions on five different chromosomes, 4.48 Mb (chromosome 2), 17.01 Mb (chromosome 3), 9.97 Mb (chromosome 6), 20.6 Mb (chromosome 9), $21.41 \mathrm{Mb}$ (chromosome 11), influenced RLSI, whereas two other QTLs $\left(q B M S I(I)_{8}\right.$ and $\left.q B M S I(I)_{12}\right)$ at $9.01 \mathrm{Mb}$ on chromosome 8 and $10.67 \mathrm{Mb}$ on chromosome 12 influenced BMSI. Of the 18 QTLs, $72 \%$ of the favorable alleles came from the recipient parent and were located on eight chromosomes $(1,2,3$, $5,8,9,11$, and 12 ), whereas $27 \%$ of such alleles, observed on chromosomes 4 and 6 , were received from the donor parent.

\section{Co-localization and clustered QTLs}

It was remarkable to note that 16 genomic regions were found to harbor two to four co-localized M-QTLs associated with several traits (Fig. 5 and Table 6). Three genomic regions mapped onto chromosomes 1,5 , and 11 were observed to carry QTLs associated with no fewer than three traits. An M-QTL at the $20.70 \mathrm{Mb}$ region on chromosome 1 was found to be co-localized with three QTLs, $q L T G S(I I)_{1}, q L T G S(I I I)_{1}$, and $q L T G(I I I)_{1}$, that explained a PV of $7.92 \%, 7.87 \%$, and $7.88 \%$. Similarly, the M-QTLs on chromosome 5 at the 28.6 Mb region harbored four QTLs, LTG (I), LTG (II), LTGS (I), SVI (I), together explaining $56.25 \%$ of the PV. Another co-mapped M-QTL on chromosome 11 at the $21.68 \mathrm{Mb}$ region was concomitant with four traits, SL, SGI, SLSI, and RLSI, and explained $30.82 \%$ of the total PV.

The co-localized QTLs $q L T G_{(I)}$ and $q S V I_{(I)}$ at $42.4 \mathrm{Mb}$ on chromosome 1, qSGI and $S L S I_{(I)}$ at $16.9 \mathrm{Mb}$ on chromosome $3, q L T G_{(I)}$ and $q L T G_{(I I)}$ at $3.85 \mathrm{Mb}$ on chromosome $7, q L T G S_{(I I I)}$ and $q S G I$ at $20.58 \mathrm{Mb}$ on chromosome $9, q R L$ and $q S V I_{(I I)}$ at $0.25 \mathrm{Mb}$ on chromosome 11, and another two QTLs $\left(q R L S I_{(I)}\right.$ and $\left.q S V I_{(I I I)}\right)$ at $21.41 \mathrm{Mb}$ on chromosome 11 explained an average PV of $10.11 \%$ and the favorable alleles were contributed by the donor parent. Similarly, co-localized regions harboring QTLs $q L T G_{(I)}$ and $q L T G S_{(I)}$ at $3.83 \mathrm{Mb}$ on chromosome 2, qLTGS $(I I)$ and $\left.q L T G S_{(I I I)}\right)$ at $3.54 \mathrm{Mb}$ on chromosome $3, q R L S I_{(I)}$ and $q B M S I$ at $21.8 \mathrm{Mb}$ on chromosome $4, q R L S I_{(I)}$ and $q B M S I$ at $9.97 \mathrm{Mb}$ and another two QTLs, $q L T G_{(I I I)}$ and $q L T G S_{(I I)}$ located at $29.2 \mathrm{Mb}$ on chromosome 6 , $q L T G_{(I)}$ and $q L T G S_{(I)}$ at $2.88 \mathrm{Mb}$ and another two QTLs, $q L T G S_{(I I)}$ and $q S G I$, at $23.7 \mathrm{Mb}$ on chromosome 8 , received desirable alleles from the recipient parent 
and explained an average PV of 9.51\%. Most of the MQTLs were growth stage-specific and located on different chromosomes and they also governed multiple traits together. Eight chromosomes (1, 2, 3, 5, 6, 8, 9, and 11) had no fewer than four QTLs clustered together and were designated as promising LTS tolerance QTLs $\left(q L T T_{S}\right)$, as $q L T T_{1}, q L T T_{2}, q L T T_{3}, q L T T_{5}, q L T T_{6}$, $q L T T_{8}, q L T T_{9}$, and $q L T T_{11}$, and they explained average of PV ranging from $8.33 \%$ (chromosome 1) to $14.06 \%$ (chromosome 5).

\section{Discussion}

Germination and early seedling growth traits are governed by a combination of multiple QTLs and genes. The complex inheritance and phenotypic expression are significantly affected by environmental factors (Cruz et al. 2006; Satoh et al. 2016; Shakiba et al. 2017; Zhao et al. 2017). Genetic dissection of potential chromosomal regions harboring QTLs related to LTS tolerance during germination and the early seedling stage is expected to reveal the genetic control of the trait. Therefore, the identification of QTLs with main effects and co-localized QTLs associated with genomic regions governing multiple traits will prove highly valuable for marker-assisted breeding (MAB) for the enhancement of LTS tolerance in rice.

Among the various abiotic stress factors, LTS is one of the major limitations of rice production, particularly in temperate and subtropical regions (Van Nguyen and Ferrero 2006; Zeng et al. 2017). Below $17^{\circ} \mathrm{C}$, rice is severely affected, mainly resulting in poor germination and seedling establishment, a severe reduction in growth, and lower yield (Andaya and Mackill 2003b; Koseki et al. 2010). Despite this fact, some rice cultivars, particularly japonica types, are known to possess LTS tolerance (Lou et al. 2007). However, some indica cultivars are shown to be more LTS tolerant than japonica cultivars (Huang et al. 2012; Pan et al. 2015). Recently, Najeeb et al. (2019) reviewed the LTS tolerance QTLs reported in rice at germination and seedling and booting stages while using different genetic backgrounds such as DHs, RIL, BILs, $\mathrm{BC}_{2} \mathrm{~F}_{1}, \mathrm{~F}_{2}$, and $\mathrm{F}_{8}$ as mapping populations. Among these populations, a few major QTLs have been identified by Andaya and Mackill (2003b), Fujino et al. (2004), Lou et al. (2007), Baruah et al. (2009), Shinada et al. (2014),
Fig. 4 Depicted representation of the distribution pattern of lowtemperature stress (LTS) tolerance QTLs associated with phenotypic traits on 12 chromosomes, The total phenotypic variance explained (PVE) of different QTL indicates in the middle part with black color font, and percentage of number QTLs (\%) distributed on 12 chromosomes were shown at the outter boundary of pie chart $(\mathrm{Chr}=$ chromosome; $\mathrm{PVE}=$ phenotypic variation explained; LTG = low-temperature germination; LTGS = low-temperature germination stress index; BMSI = biomass stress index; $\mathrm{SL}=$ shoot length; $\mathrm{RL}=$ root length; SLSI = shoot length stress index; RLSI = root length stress index; SGI = shoot growth index; $\mathrm{SVI}=$ seedling vigor index)

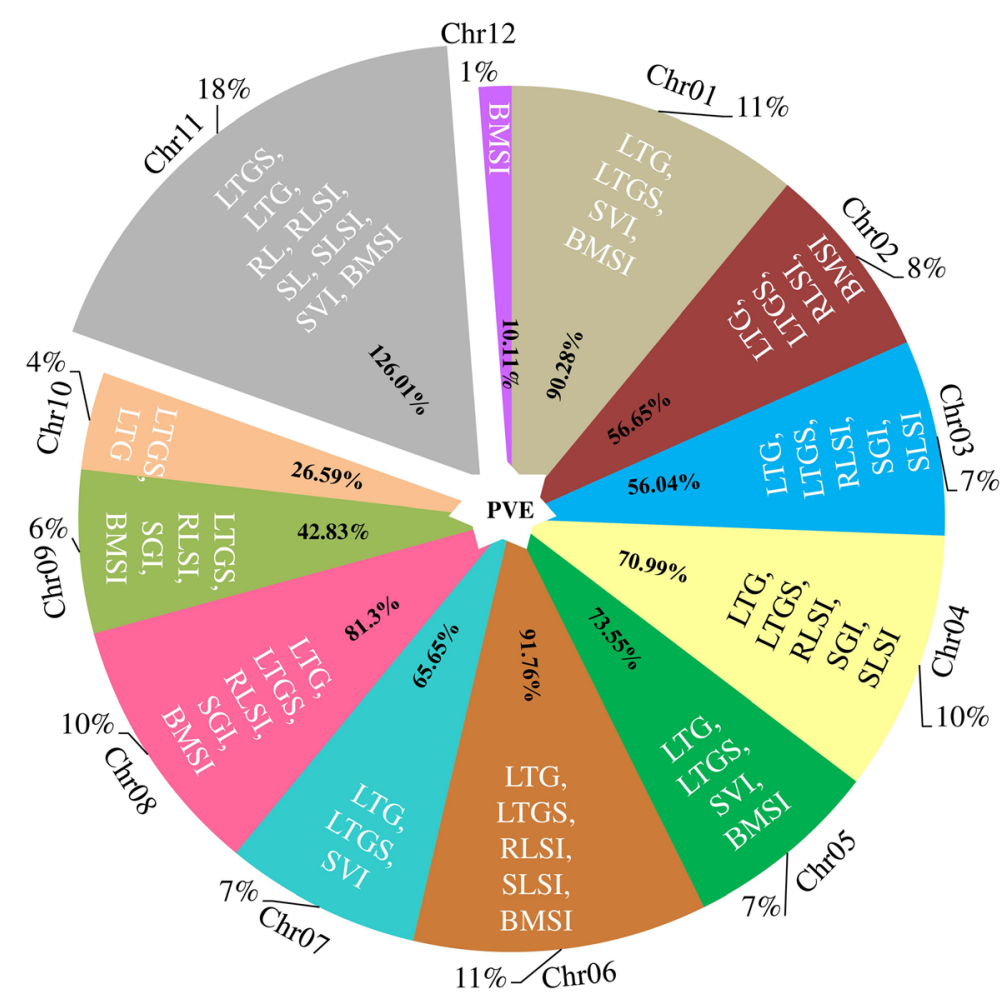


Jiang et al. (2017), and Shakiba et al. (2017). However, there are no significant main-effect QTLs related to the interaction of different QTLs for germination and seedling growth traits. Detailed information on M-QTLs and co-localized QTLs associated with multiple traits may provide a better understanding of LTS tolerance, and this is an essential step toward developing cultivars with superior LTS tolerance and enhancing rice production in regions where low-temperature limits rice yield.
Phenotypic and genotypic variation of LTS tolerance traits

In the current study, significant phenotypic variations were observed in the ILs for cold tolerance and a tendency of most of the traits in LTG and SVI stages toward a normal distribution. The ILs exhibited transgressive segregation for all the traits and mean values of the ILs were found to be intermediate between those of the parental lines, WTR-1 and HNG (Table 2), suggesting

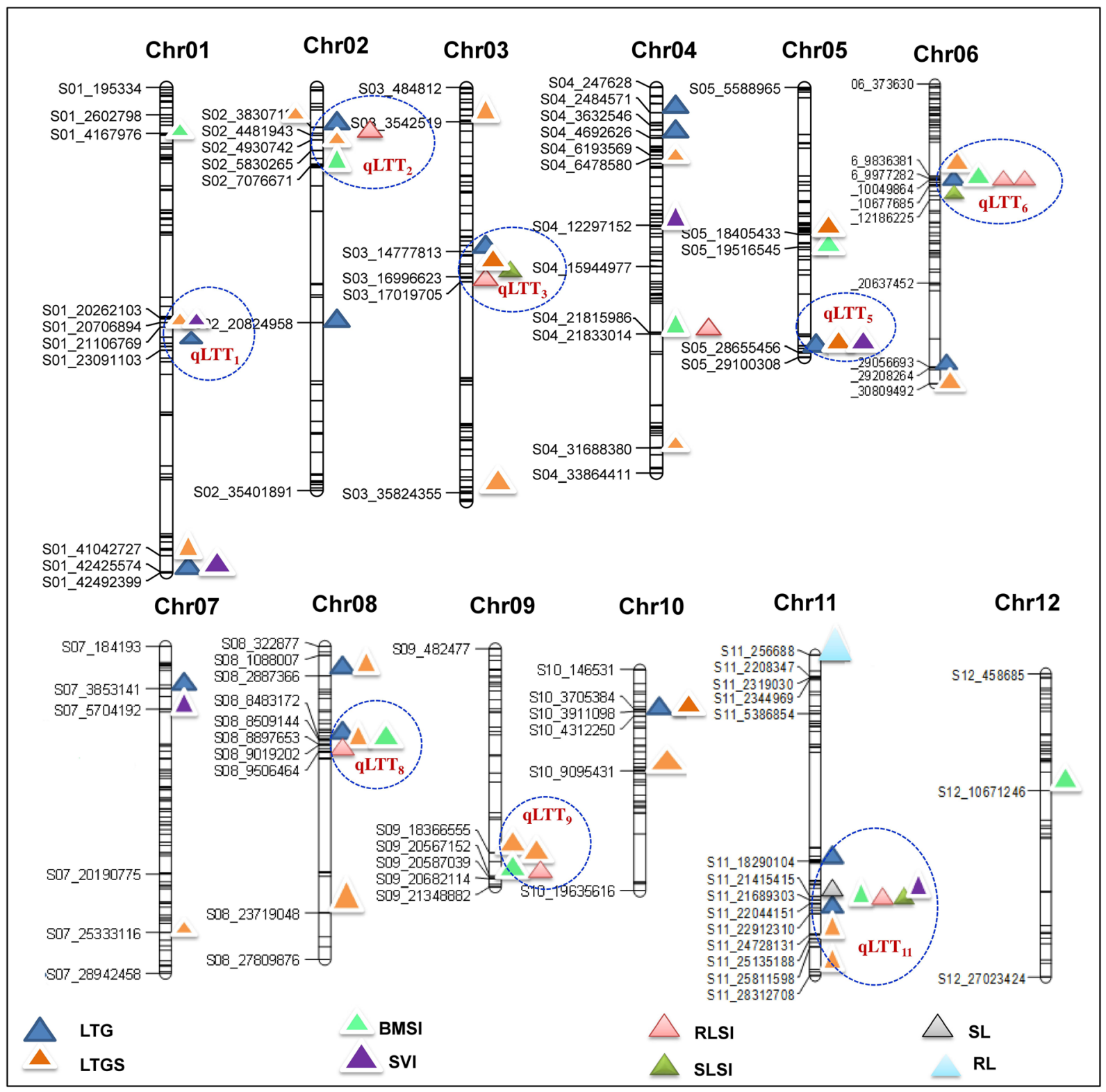

Fig. 5 Linkage map and chromosomal position of QTLs (LOD score of $\geq 3$ ) for LTS tolerance in rice. Circles indicate the clustered QTLs located on eight different chromosomes 
a polygenic inheritance of the traits. The pattern of transgressive segregation was, in fact, the contribution of either of the parents in the form of favorable or unfavorable alleles for specific traits in the ILs (Rieseberg et al. 2003). A strong positive correlation was observed in LTG with RL, SL, BM, and SVI. Further, among the ILs, 24 promising lines showed a significantly higher germination rate under cold stress in all three stages (Fig. 1). The high variability in LTG, SL, RL, and SVI in the ILs and their normal distribution pattern were considered for selecting better genotypes and for undergoing QTL analysis for cold tolerance. The positive skewness of LTG-I, LTG-II at 2 and 4 DAS, and SL-I, RL-I, and SVI-II at 10 DAS, SVI at 13 DAS, and SVI and BW at 16 DAS suggests complementary gene action while the negative skewness of LTG-III, SL-II, and RL-II at 13 DAS and SL-III and RL-III at 16 DAS is associated with duplicate (additive $\times$ additive) gene action. The strong relationship of LTG, RL, BM, RLSI, and SVI indicates the possibility of common QTLs/genes regulated at the molecular level.

Genetic analysis of LTS tolerance revealed a total of 82 QTLs associated with 16 traits in three different growth stages and they were distributed on all 12 chromosomes. The PV explained ranged from 6.95 to $23.38 \%$ and LOD value from 3.0 to 11.1 , while no QTLs were identified for the remaining 12 traits (SL-I, III; SLSI-II, III; RL-II, III; RLSI-III; AG-I, II, and III; RGR-I and II) perhaps due to the non-significant difference among the ILs for such traits. Of these 82 QTLs, 27 main-effect QTLs (M-QTLs) identified on 12 chromosomes. These QTLs were significantly associated with LTG, LTGS, RLSI, and BMSI. Among the total number of QTLs, only five were identified as major M-QTLs (LOD $>7.0$ and PV explained $>15 \%$ ) and they were governing germination-related traits LTG(I) (LOD $7.31_{1}$ and $16.08 \%$ ), LTGS(I) $)_{1-2}$ (LOD 7.55 and 16.57\%), LTG(I) $)_{5}($ LOD 8.56 and $18.56 \%)$, LTGS(I) $)_{5}$ (LOD 11.1 and $23.38 \%$ ), and LTG(I) 7 (LOD 9.3\% and $20.12 \%$ ) on three chromosomes $(1,5$, and 7$)$, respectively. The favorable alleles for all these major QTLs were contributed by HAN, indicating the possibility of using this variety as a parent in future breeding programs. In different growth stages, the stability of MQTLs is an imperative factor when deciding on the use of QTLs in breeding programs. The major M-QTLs governing germination rate in two stages, LTG(I) and LTG(II), were identified on chromosome 5 in the genomic region 28.6 Mb. Another major stable M-QTL was identified on chromosome 7 (3.85 Mb) for LTG(I) and LTG(II) with PV explained of $20.12 \%$ and $8.25 \%$ and LOD value of 9.37 and 3.59. Likewise, a few M-QTLs with relatively higher PV explained were consistently governing two stages, such as LTGS(II) and LTGS(III) $(20.70 \mathrm{Mb})$ on chromosome 1 and LTGS(II) and LTGS(III) on chromosome 3. In earlier reports, Fujino et al. (2008), Li et al. (2013), Cui et al. (2013), Shinada et al. (2014), and Zhu et al. (2015) mentioned a few stable QTLs across several environments under LTS. The importance of stable QTLs is that they have larger additive effects and are less affected by the environment.

Co-localized and pleiotropic M-QTLs located in adjacent regions on the chromosome govern multiple traits, which are most prominent for the concurrent improvement of multiple traits (Shakiba et al. 2017; Li et al. 2018; Liang et al. 2018). In this study, eight clusters of M-QTLs or pleiotropic M-QTLs were identified on different chromosomes governing simultaneously different traits: LTG(III) + LTGS(I) + LTGS(II) + LTGS(III) + SVI(I) (chromosome 1), LTG(I) + LTGS(I) + LTGS(III) + RLS(I) + BMSI (chromosome 2), LTG(III) + RLSI(I) + SGI + SLSI(I) (chromosome 3), LTG(I) + LTG(II) + LTGS(I) + SVI(I) (chromosome 5), LTG(I) + LTGS(I) + RLSI(I) + RLSI(II) + BMSI (chromosome 6), LTG(III) + LTGS(III) + RLSI(I) + BMSI (chromosome 8), LTGS(III) + RLSI(I) + SGI + BMSI (chromosome 9), and RLSI(I) + RLSI(II) + SL(II) + SLSI(I) + SVI(III) + BMSI (chromosome 11). From the total of 61 genomic regions, 16 regions were associated with two to four germination- and seedling growth-related traits, and they were co-localized. These co-localized QTLs were identified in earlier studies on cold tolerance germination and yield component traits in rice (Andaya and Mackill 2003a, b; Koseki et al. 2010; Wang et al. 2016a; Shakiba et al. 2017). Several major lowtemperature germination and seedling-stage QTLs have been distributed widely on all 12 chromosomes using bi-parental mapping populations and diverse rice genetic resources (Teng et al. 2001; Chen et al. 2006; Liang et al. 2006, 2018; Fujino et al. 2008; Pan et al. 2015; Jiang et al. 2017; Shakiba et al. 2017; Li et al. 2018). Among the total of 82 M-QTLs, $67 \%$ of the M-QTLs received favorable alleles from donor parent $\mathrm{HNG}$, which is significant in LTS tolerance. Therefore, HNG is a novel potential resource for cold tolerance. Similarly, several researchers have used different sources of rice cultivars against cold tolerance such as 
Dongxiang wild rice (Oryza rufipogon) (Mao et al. 2015; Yu et al. 2018), Kasalath (Miura et al. 2001), AAV002863 (Lou et al. 2007), USSR 5 (Li et al. 2013), Italica Livorno (Fujino et al. 2004), M-202 (Andaya and Mackill 2003a), Kunmingxiaobaigu (Zhou et al. 2010), Hokkai-PL9 (Kuroki et al. 2007), Lijiangxintuanheigu (Zhang et al. 2014b), 2014), Hyogo-kitanishiki (Ranawake et al. 2014), and variety Geng (Meng et al. 2013).

Previously identified major QTLs qCTS-2 (PVE 27.42\%) (Lou et al. 2007) and $q$ CTS2(2) (PVE 22.9\%) (Ranawake et al. 2014) were also identified in the present study in the form of clustered QTLs harbored by chromosome 2. Similarly, on chromosome 3 ( $q L T G-3-$ $1,35.1 \%$, and $q L T G-3-2,19.3 \%$ ) (Fujino et al. 2004), chromosome 4 ( $q$ CTS4-1, 20.8\%) (Andaya and Mackill 2003a), chromosome 6 (qCTS6-1,15.3\%) (Andaya and Mackill 2003b), chromosome 7 ( $q$ CTS7(2), 35.3\%; Ranawake et al. 2014, and $q C T S 7-1,21 \%$; Zhou et al. 2010), chromosome 8 ( $q C T B 8,26.6 \%)$ (Kuroki et al. 2007), chromosome 10 ( $q R C 10-2,32.1 \%$ ) (Xiao et al. 2014), chromosome 11 (qCTS-11, 23.1\%; Zhang et al. 2014b; and $q \operatorname{CTS11}(1)-1,22.2 \%$, and $q C T S 11(1)-2$, $35.6 \%$ ) (Ranawake et al. 2014), and chromosome 12 $(q$ CTS12a $40.6 \%$ ) (Andaya and Mackill 2003a) were significantly allied in the clustered M-QTLs.

Prime M-QTLs for future breeding programs

In the present study, 82 QTLs were mapped on 61 genomic regions, with an average PV of $9.65 \%$. Eight chromosomes (1, 2, 3, 5, 6, 8, 9, and 11) harbored more than four LTS tolerance QTLs ( $q L T T S$ ). Also, $76.9 \%$ of the favorable alleles with additive effects were contributed by donor parent HNG to the total QTLs. The average PV explained by the nine QTLs $(8.45 \%)$ on chromosome 11 at 21.41 to $22.04 \mathrm{Mb}$ of the M-QTLs and co-localized with QTLs related to LTG, RLSI, SVI, SLSI, SL, and SGI. The present results are closely associated with the early seedling growth-related QTLs $q C T S 11(1)-2$ and $q$ CTS11(2)-2 (Ranawake et al. 2014) and germination QTL $q$ CTGERM11-5 under cold stress (Shakiba et al. 2017). Further, two major M-QTLs, $q L T G(I)_{1}(16.08 \%)$ and $q L T G S(I-I I)_{1}(16.57 \%)$, on chromosome 1 at the 41.0 to $42.4 \mathrm{Mb}$ region were clearly associated with the germination and seedling tolerance QTLs $q$ CTGERM1-8 and qCTS1-5 and the other QTLs $q S W 1-1$ to $q S W 1-4$ (seed weight per plant) and $q$ SWTCT1-1 (seed weight per panicle) expressed in the same genomic region under cold stress at the reproductive stage (Cui et al. 2013; Yang et al. 2016; Shakiba et al. 2017). Similarly, two other QTLs, $q L T G(I)_{5}$ $(18.56 \%)$ and $q L T G S(I)_{5}(23.38 \%)$, on chromosome 5 at the $28.65 \mathrm{Mb}$ region were concomitant with qSWTNCT5 (seed weight per panicle), qCTB5 (cold tolerance at booting stage), and seedling-stage QTLs qCTSR5-1 (cold tolerance seed survival rate) and qCTSD5-2 (cold tolerance severity of damage) (Andaya and Mackill 2003b; Ranawake et al. 2014; Shakiba et al. 2017; Zhang et al. 2018b). Lastly, $q L T G(I)_{7}(20.12 \%)$ located on chromosome 7 at $3.85 \mathrm{Mb}$ is a novel locus, which is co-localized with second germination stage QTL LTG(II) $(8.25 \%)$. To date, there is no previously reported QTL on this genomic position, but Ranawake et al. (2014) observed a major QTL, $q$ CTS7(2), on the same chromosome at the 17.4 $\mathrm{Mb}$ position, which is associated with seedlingstage cold stress. Furthermore, the M-QTLs identified in our study are very precise and stable because phenotyping of all traits was carried out in a growth chamber for a prolonged period (16 days) as compared to the relatively shorter periods of cold treatment in earlier studies (Lee 2001; Han et al. 2004; Chen et al. 2006; Bosetti et al. 2012; Pouramir et al., 2013; Xiao et al. 2014; Xie et al. 2014). It is noteworthy that, so far no QTLs have been detected for LTS germination associated with SVI and BMSI in the near genomic regions/co-localization of MQTLs. On chromosome 1 (20.7 Mb) and chromosome 5, QTLs are co-localized governing traits such as LTG, LTGS, and SVI, and on chromosome 11, they are colocalized with LTG, SVI, BMSI, SLSI, and SGI at the 21.6-22.0 Mb position. Therefore, co-localized/clustered QTLs of genomic regions governing multiple traits are most useful for introgression into elite high-yielding breeding varieties to breed for LTS tolerance, particularly for germination and early seedling growth stages.

Putative candidate genes of major M-QTLs

Among the five major M-QTLs (> 15\% PVE), two QTLs each on chromosome 1 (41.04 Mb), and chromosome $5(28.65 \mathrm{Mb})$, and single QTL on chromosome 7 $(3.85 \mathrm{Mb})$ are co-localized with M-QTLs on 16 genomic regions were fine-tuned for their peak marker position to identify possible candidate genes using the Rice Annotation Project Database (RAP-DB, http://rapdb. dna.affrc.go.jp/). There are three putative genes for major M-QTLs and 11 gene for co-localized QTLs of 


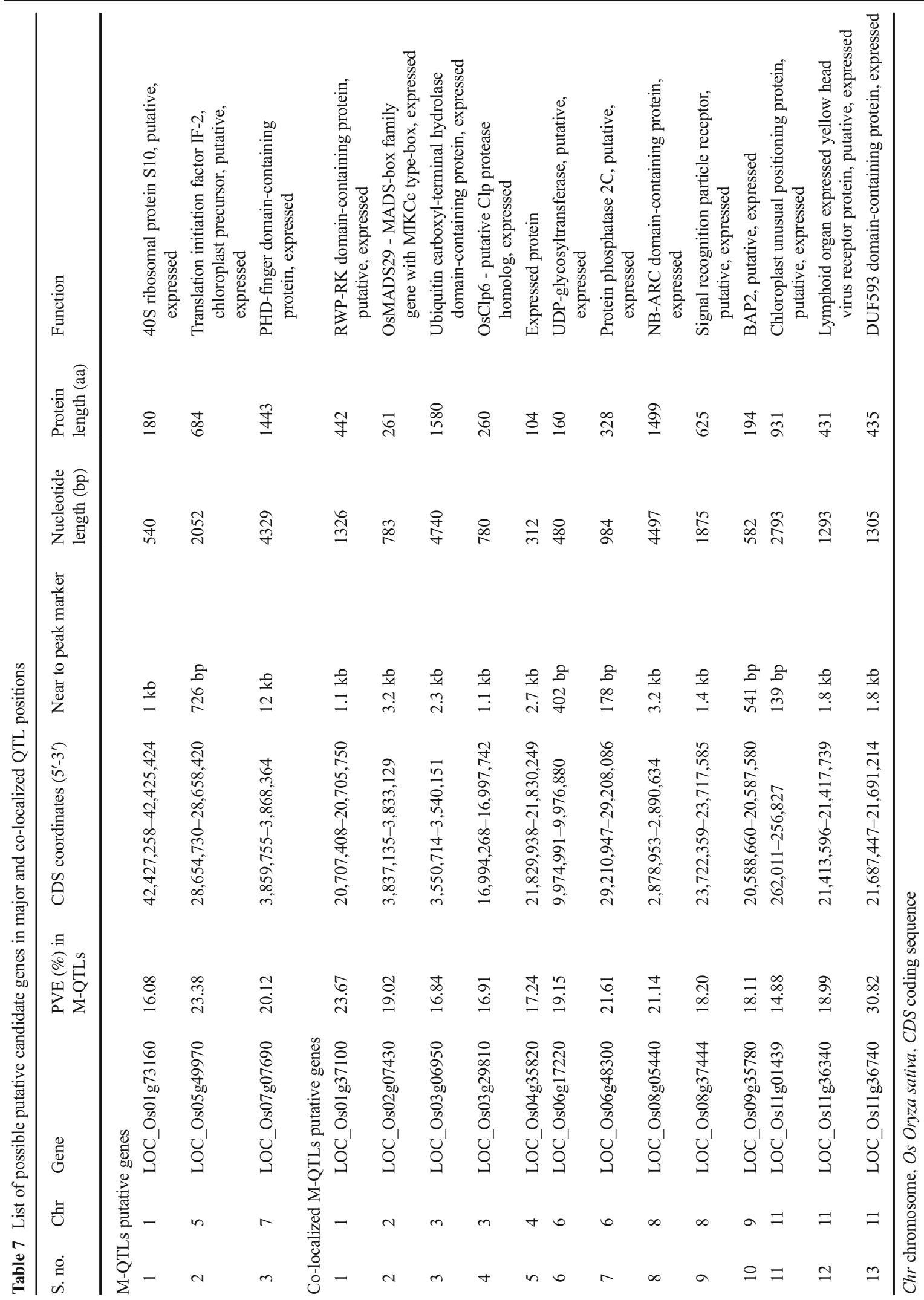


each chromosome (Table 7). The QTLs with largest PV on chromosome 5 at $28.65 \mathrm{Mb}(23.38 \%)$ had possible candidate gene LOC_Os05g49970 encoding translation initiation factor-2 (eIF2) involved in various growth developmental stages such as xylogenesis, flowering, sporogenesis, and germination, and also interacting with various abiotic stresses (Martínez-Silva et al. 2012; Mutuku et al. 2015) and hormonal signaling pathways in plant defense mechanisms (Lv et al. 2014). The eIF2 involved in the physiological and metabolic pathway is rapidly expressed during the germination process such as water uptake, mobilization, and the breakdown of storage reserves of energy compounds for the expansion of the embryo (Dogra et al. 2015; Qian et al. 2015). Further, it is implicated in the formation of the largest eIF3, the 40S subunit, which is responsible for recruiting mRNA to the $43 \mathrm{~S}$ pre-initiation complex and recognizing AUG during protein synthesis (Hinnebusch 2006; Wang et al. 2016c). A recent study of Wang et al. (2016c) mentioned that the OseIF3e gene significantly regulates seedling growth during the vegetative stage and also influences the development of organ size and pollen maturation.

In a similar way, LOC_Os01g73160, another gene, which is $1 \mathrm{~kb}$ away from the peak marker position of major QTL $q L T G S(I)_{1-2}(16.57 \%)$ on chromosome 1, is the locus associated with ribosomal protein-small subunit (RPS-10), mainly involved in the abiotic stress tolerance mechanism and also in the development of the vegetative growth stage in leaves and shoots (Moin et al. 2016; Saha et al. 2017). To date, 34 RPS have been identified, which encode to 123 genes containing multiple copies of genes in rice. However, seven genes (RPS4, 7, 8, 9, 10, 19, and 26) were early responsive genes that were significantly upregulated under salinity stress (Kawasaki et al. 2001; Saha et al. 2017). Another major locus on chromosome 7, $4.0 \mathrm{~kb}$ away from the peak marker, encodes PHD-finger domain-containing protein locus (LOC_Os07g07690), encodes the transcription factor involved in submergence stress tolerance mechanism (Sharma et al. 2018).

Putative candidate genes in co-localized M-QTLs

The co-localized QTLs are associated with multiple functional roles in the physiology related to ABA synthesis, responses to plant growth regulators, the formation of chloroplast, and tolerance of biotic and abiotic stresses. The major role of possible candidate genes on chromosome 1 (LOC_Os01g37100) encoding the RWP-RK domain is involved in early regulation of cellular responses to $\mathrm{N}$ supply and low phosphate availability (Castaings et al. 2009; Chardin et al. 2014). Chromosome $2(3.83 \mathrm{Mb})$ is associated with OsMADS29 - MADS-box family gene (LOC_Os02g07430), which encodes for a putative Bsister-type MIKCc transcription factor, mainly involved in the seed development. The LOC_OsO2g07430 is responsible for the regulation of starch biosynthesis during the process of seed development by regulating the cytokinin levels (Agarwal et al. 2016: Chen et al. 2013). Sharma et al. (2012) and Nayar et al. (2013) reported that the OsMADS29 gene regulates the hormone homeostasis and starch filling in endosperm cells. Similarly, at $3.54 \mathrm{Mb}$, LOC_Os03g06950 is responsible for auxin signaling pathways in shoot development and also early development of rice stamens (Yang et al. 2007; Wang et al. 2018). Another locus encodes to LOC_Os03g29810, which controls several functions in the synthesis of plastidic proteins in the chloroplast and regulates the photosynthesis mechanism (Dong et al. 2013; van Campen et al. 2016). Two genes on chromosome 6 (LOC_Os06g17220 and LOC_Os06g48300) are responsible for sucrose synthetic activity and tolerance of anoxia condition during germination (LasanthiKudahettige et al. 2007) and regulate the major ABAdependent signaling component, which is involved in a high rate of germination (Bhatnagar et al. 2017). Singh et al. (2015) revealed that the OSPP108 gene of the PP2C family significantly enhanced tolerance of drought, cold, and salinity during seed germination. On chromosome 8 , LOC_Os08g05440 is associated with resistance to biotic stresses and chloroplast degradation (van der Biezen and Jones 1998; Jiao et al. 2012). Lastly, LOC_Os11g01439 on chromosome 11 is involved in the intracellular changes of chloroplast position (Oikawa et al. 2003) and has a potential role in the formation of protein bodies in the endosperm and the interaction of myosin (Peremyslov et al. 2013). Therefore, a further expression and fine mapping of potential candidate genes/alleles may provide valuable information for increasing LTS tolerance during the embryo burst stage and seedling growth stage in rice.

\section{Conclusions}

Significant M-QTLs for different stages of germination and seedling growth-related traits under LTS conditions were identified in the specific genomic regions of 
different chromosomes. Exposure to cold stress for 16 days resulted in the identification of 24 ILs as the most promising lines with more than $90 \%$ germination. During the early growth stages of cold stress, GR, RL, SL, BM, and SVI were highly significant and strongly associated with each other. Of the 82 QTLs, five major M-QTLs were located on chromosomes 1, 5, and 7, and 16 genomic regions co-localized with two to four traits were also observed in the present study. The highest number of QTLs was located on chromosome 11, followed by chromosomes 1 and 6 . Three possible candidate genes for major M-QTLs and 13 genes from co-localized M-QTL positions are associated with the combination of multiple traits. This genomic information is highly valuable for the fine mapping and validation of gene expression under LTS. However, promising ILs in the present study could be crossed with coldsensitive elite cultivars to develop desirable recombinants for cultivation in temperate and highaltitude and high-latitude regions. In addition, designed QTL pyramiding will be carried out by inter-crossing the introgression lines and pooling the M-QTLs into pyramiding lines. For the use of MAS, there is an urgent need to fine-map the genomic region, identify genes, and alleles, and further develop functional markers for the improvement of cold tolerance in rice.

Acknowledgments The authors would like to thank those who participated in the internal review of the manuscript at the International Rice Research Institute and two anonymous reviewers from the Molecular Breeding journal for improving it through their valuable suggestions.

Author contribution statement SN conducted a phenotypic experiment in plant growth chamber facilities at IRRI and generated phenotypic data and analyzed them with assistance from YLP, JZ, VM, and AM. SN and AM prepared the outline of the content in the draft and wrote the manuscript with advice from LRV and JA. JA conceptualized and designed this study. JA and ZL revised the manuscript. All authors read and approved this article.

Funding information This study received financial support from the Bill \& Melinda Gates Foundation (BMGF ID OPP1130530) and the Department of Science and Technology (DOST)-Philippine Council for Agriculture, Aquatic, and Natural Resources Research and Development (PCCARRD), Philippines, for providing funds to JA through the University of the Philippines, Los Baños (UPLB), under the improved resource use efficient (iRUE) rice project.

\section{Compliance with ethical standards}

Conflict of interest The authors declare that they have no conflict of interest.
Ethical standards We declare that the present experiments comply with the ethical standards of the International Rice Research Institute (IRRI), Philippines.

Open Access This article is licensed under a Creative Commons Attribution 4.0 International License, which permits use, sharing, adaptation, distribution and reproduction in any medium or format, as long as you give appropriate credit to the original author(s) and the source, provide a link to the Creative Commons licence, and indicate if changes were made. The images or other third party material in this article are included in the article's Creative Commons licence, unless indicated otherwise in a credit line to the material. If material is not included in the article's Creative Commons licence and your intended use is not permitted by statutory regulation or exceeds the permitted use, you will need to obtain permission directly from the copyright holder. To view a copy of this licence, visit http://creativecommons.org/licenses/by/ $4.0 \%$.

\section{References}

Abdul-Baki AA, Anderson JD (1973) Vigor determination in soybean seed by multiple criteria 1. Crop Sci 13:630-633

Abhinandan K, Skori L, Stanic M et al (2018) Abiotic stress signaling in wheat-an inclusive overview of hormonal interactions during abiotic stress responses in wheat. Front Plant Sci 9

Agarwal P, Parida SK, Raghuvanshi S, Kapoor S, Khurana P, Khurana JP, Tyagi AK (2016) Rice improvement through genome-based functional analysis and molecular breeding in India. Rice. 9(1):1. https://doi.org/10.1186/s12284-0150073-2

Ali J, Aslam UM, Tariq R et al (2018) Exploiting the genomic diversity of rice (Oryza sativa L.): SNP-typing in 11 earlybackcross introgression-breeding populations. Front Plant Sci 9. https://doi.org/10.3389/fpls.2018.00849

Ali J, Franje NJ, Revilleza JE, Acero B (2016) Breeding for lowinput responsive green super rice (GSR) varieties for rainfed lowlands of Asia and Africa. Philipp J Crop Sci 42:34

Anbumozhi V, Breiling M, Pathmarajah S, Reddy VR (2012) Climate change in Asia and the Pacific: how can countries adapt? SAGE Publications, India, p 363

Andaya V, Mackill D (2003a) QTLs conferring cold tolerance at the booting stage of rice using recombinant inbred lines from a japonica $\times$ indica cross. Theor Appl Genet 106:1084-1090

Andaya VC, Mackill DJ (2003b) Mapping of QTLs associated with cold tolerance during the vegetative stage in rice. J Exp Bot 54:2579-2585. https://doi.org/10.1093/jxb/erg243

Andaya VC, Tai TH (2006) Fine mapping of the qCTS12 locus, a major QTL for seedling cold tolerance in rice. Theor Appl Genet 113:467-475

Baruah AR, Ishigo-Oka N, Adachi M et al (2009) Cold tolerance at the early growth stage in wild and cultivated rice. Euphytica 165:459-470

Bhatnagar N, Min MK, Choi EH, Kim N, Moon SJ, Yoon I, Kwon T, Jung KH, Kim BG (2017) The protein phosphatase 2C 
clade A protein OsPP2C51 positively regulates seed germination by directly inactivating OsbZIP10. Plant Mol Biol 93: 389-401

Bonnecarrere V, Quero G, Monteverde E et al (2015) Candidate gene markers associated with cold tolerance in vegetative stage of rice (Oryza sativa L.). Euphytica 203:385-398

Bosetti F, Montebelli C, Novembre ADLC, Chamma HP, Pinheiro JB (2012) Genetic variation of germination cold tolerance in Japanese rice germplasm. Breed Sci 62:209-215

Castaings L, Camargo A, Pocholle D, Gaudon V, Texier Y, BoutetMercey S, Taconnat L, Renou JP, Daniel-Vedele F, Fernandez E, Meyer C, Krapp A (2009) The nodule inception-like protein 7 modulates nitrate sensing and metabolism in Arabidopsis. Plant J 57:426-435

Chardin C, Girin T, Roudier F, Meyer C, Krapp A (2014) The plant RWP-RK transcription factors: key regulators of nitrogen responses and of gametophyte development. J Exp Bot 65:5577-5587

Chen L, Lou Q-J, Sun Z et al (2006) QTL mapping of low temperature on germination rate of rice. Rice Sci 13:93-98

Chen Y, Xu Y, Luo W, Li W, Chen N, Zhang D, Chong K (2013) The F-box protein OsFBK12 targets OsSAMS1 for degradation and affects leaf senescence and seed size in rice. Plant Physiol 163:1673-1685

Counce PA, Keisling TC, Mitchell AJ (2000) A uniform, objective, and adaptive system for expressing rice development. Crop Sci 40:436-443

da Cruz RP, Milach SCK (2004) Cold tolerance at the germination stage of rice: methods of evaluation and characterization of genotypes. Sci Agric 61:1-8

da Cruz RP, Milach SCK, Federizzi LC (2006) Rice cold tolerance at the reproductive stage in a controlled environment. Sci Agric 63:255-261

da Cruz RP, Sperotto RA, Cargnelutti D et al (2013) Avoiding damage and achieving cold tolerance in rice plants. Food Energy Secur 2:96-119

Cui D, Xu C, Tang C et al (2013) Genetic structure and association mapping of cold tolerance in improved japonica rice germplasm at the booting stage. Euphytica 193:369-382. https://doi.org/10.1007/s10681-013-0935-x

Dimaano NGB, Ali J, Cruz PCSS et al (2017) Performance of newly developed weed-competitive rice cultivars under lowland and upland weedy conditions. Weed Sci 65:798-817. https://doi.org/10.1017/wsc.2017.57

Dogra V, Bagler G, Sreenivasulu Y (2015) Re-analysis of protein data reveals the germination pathway and up accumulation mechanism of cell wall hydrolases during the radicle protrusion step of seed germination in Podophyllum hexandrum-a high altitude plant. Front Plant Sci 6:874

Dong H, Fei GL, Wu CY, Wu FQ, Sun YY, Chen MJ, Ren YL, Zhou KN, Cheng ZJ, Wang JL, Jiang L, Zhang X, Guo XP, Lei CL, Su N, Wang H, Wan JM (2013) A rice virescentyellow leaf mutant reveals new insights into the role and assembly of plastid Clp protease in higher plants. Plant Physiol 162:1867-1880

Donoso G, Cabas P, Paredes M et al (2015) Cold tolerance evaluation of temperate rice (Oryza sativa L. ssp. japonica) genotypes at seedling stage. Gayana Bot 72:1-13

Feng B, Chen K, Cui Y, Wu Z, Zheng T, Zhu Y, Ali J, Wang B, Xu J, Zhang W, Li Z (2018) Genetic dissection and simultaneous improvement of drought and low nitrogen tolerances by designed QTL pyramiding in rice. Front Plant Sci 9:306. https://doi.org/10.3389/fpls.2018.00306

Fujino K, Matsuda Y (2010) Genome-wide analysis of genes targeted by qLTG3-1 controlling low-temperature germinability in rice. Plant Mol Biol 72:137-152

Fujino K, Sekiguchi H, Matsuda Y, Sugimoto K, Ono K, Yano M (2008) Molecular identification of a major quantitative trait locus, qLTG3-1, controlling low-temperature germinability in rice. Proc Natl Acad Sci 105:12623-12628. https://doi. org/10.1073/pnas.0805303105

Fujino K, Sekiguchi H, Sato T et al (2004) Mapping of quantitative trait loci controlling low-temperature germinability in rice (Oryza sativa L.). Theor Appl Genet 108:794-799

Glaszmann J-C, Kaw RN, Khush GS (1990) Genetic divergence among cold tolerant rices (Oryza sativa L.). Euphytica 45: 95-104

Han LZ, Qiao YL, Cao GL et al (2004) QTLs analysis of cold tolerance during early growth period for rice. Rice Sci 11: 245-250

Hasanuzzaman M, Nahar K, Biswas JK et al (2009) Screening of Indica Rice (Oryza sativa L.) genotypes against low temperature stress. Bot Res Int 2:295-303

Hinnebusch AG (2006) eIF3: a versatile scaffold for translation initiation complexes. Trends Biochem Sci 31:553-562

Huang X, Zhao Y, Li C et al (2012) Genome-wide association study of flowering time and grain yield traits in a worldwide collection of rice germplasm. Nat Genet 44:32-39

Jena KK, Kim SM, Suh JP et al (2012) Identification of coldtolerant breeding lines by quantitative trait loci associated with cold tolerance in rice. Crop Sci 52:517-523

Ji Z, Zeng Y, Zeng D et al (2010) Identification of QTLs for rice cold tolerance at plumule and 3-leaf-seedling stages by using QTLNetwork software. Rice Sci 17:282-287

Jewel ZA, Ali J, Pang Y et al (2019) Developing green super rice varieties with high nutrient use efficiency by phenotypic selection under varied nutrient conditions. Crop J 7:368-377

Jiang N, Shi S, Shi H, Khanzada H, Wassan GM, Zhu C, Peng X, Yu Q, Chen X, He X, Fu J, Hu L, Xu J, Ouyang L, Sun X, Zhou D, He H, Bian J (2017) Mapping QTL for seed germinability under low temperature using a new high-density genetic map of rice. Front Plant Sci 8:1223. https://doi. org/10.3389/fpls.2017.01223

Jiang W, Jin Y-M, Lee J et al (2011) Quantitative trait loci for cold tolerance of rice recombinant inbred lines in low temperature environments. Mol Cells 32:579-587

Jiao BB, Wang JJ, Zhu XD et al (2012) A novel protein RLS1 with NB-ARM domains is involved in chloroplast degradation during leaf senescence in rice. Mol Plant 5:205-217

Kawasaki S, Borchert C, Deyholos M et al (2001) Gene expression profiles during the initial phase of salt stress in rice. Plant Cell 13:889-905

Kim SM, Suh JP, Lee CK et al (2014) QTL mapping and development of candidate gene-derived DNA markers associated with seedling cold tolerance in rice (Oryza sativa L.). Mol Gen Genomics 289:333-343. https://doi.org/10.1007 /s00438-014-0813-9

Koseki M, Kitazawa N, Yonebayashi S, Maehara Y, Wang ZX, Minobe Y (2010) Identification and fine mapping of a major quantitative trait locus originating from wild rice, controlling cold tolerance at the seedling stage. Mol Gen Genomics 284: $45-54$ 
Kuroki M, Saito K, Matsuba S, Yokogami N, Shimizu H, Ando I, Sato Y (2007) A quantitative trait locus for cold tolerance at the booting stage on rice chromosome 8 . Theor Appl Genet 115:593-600

Lasanthi-Kudahettige R, Magneschi L, Loreti E et al (2007) Transcript profiling of the anoxic rice coleoptile. Plant Physiol 144:218-231

Lee MH (2001) Low temperature tolerance in rice: the Korean experience. In: Fukai S, Basnayake J (eds) ACIAR Proceedings 101; increased lowland rice production in the Mekong region, vol ACT 2601. Australian Center for International Agricultural Research, GPO Box 1571, Canberra, pp 138-146

Li JJ, Pan Y, Guo H et al (2018) Fine mapping of QTL qCTB10-2 that confers cold tolerance at the booting stage in rice. Theor Appl Genet 131:157-166

Li L, Liu X, Xie K, Wang Y, Liu F, Lin Q, Wang W, Yang C, Lu B, Liu S, Chen L, Jiang L, Wan J (2013) qLTG-9, a stable quantitative trait locus for low-temperature germination in rice (Oryza sativa L.). Theor Appl Genet 126:2313-2322

Li T, Ali J, Marcaida M et al (2016) Combining limited multiple environment trials data with crop modeling to identify widely adaptable rice varieties. PLoS One 11:e0164456. https://doi. org/10.1371/journal.pone.0164456

Li ZK (2001) QTL mapping in rice: a few critical considerations. Rice genetics. In: Khush GS, Brar DS, Hrady B (eds) Proc 4th Int Rice Genet Symp. IRRI, Los Banos, pp 153-171

Liang C, Qiao-jun L, Zong-xiu S et al (2006) QTL mapping of low temperature germinability in rice. Zhongguo Shuidao Kexue 20:159-164

Liang Y, Meng L, Lin X et al (2018) QTL and QTL networks for cold tolerance at the reproductive stage detected using selective introgression in rice. PLoS One 13:e200846

Lou Q, Chen L, Sun Z et al (2007) A major QTL associated with cold tolerance at seedling stage in rice (Oryza sativa L.). Euphytica 158:87-94. https://doi.org/10.1007/s10681-0079431-5

Luo Q (2011) Temperature thresholds and crop production: a review. Clim Chang 109:583-598

Lv W, Du B, Shangguan X et al (2014) BAC and RNA sequencing reveal the brown planthopper resistance gene BPH15 in a recombination cold spot that mediates a unique defense mechanism. BMC Genomics 15:674

Lv Y, Guo Z, Li X et al (2016) New insights into the genetic basis of natural chilling and cold shock tolerance in rice by genome-wide association analysis. Plant Cell Environ 39: $556-570$

Mao D, Yu L, Chen D, Li L, Zhu Y, Xiao Y, Zhang D, Chen C (2015) Multiple cold resistance loci confer the high cold tolerance adaptation of Dongxiang wild rice (Oryza rufipogon) to its high-latitude habitat. Theor Appl Genet 128:1359-1371. https://doi.org/10.1007/s00122-015-2511-3

Martínez-Eixarch M, Ellis RH (2015) Temporal sensitivities of rice seed development from spikelet fertility to viable mature seed to extreme-temperature. Crop Sci 55:354-364. Doi: https://doi.org/10.2135/cropsci2014.01.0042. doi: https://doi.org/10.1186/1471-2164-15-674

Martínez-Silva AV, Aguirre-Martínez C, Flores-Tinoco CE, Alejandri-Ramírez ND, Dinkova TD (2012) Translation initiation factor ateiF(iso)4E is involved in selective mRNA translation in arabidopsis thaliana seedlings. PLoS One 7: e31606. https://doi.org/10.1371/journal.pone.0031606

Meena KK, Sorty AM, Bitla UM et al (2017) Abiotic stress responses and microbe-mediated mitigation in plants: the omics strategies. Front Plant Sci 8:172

Meng L, Li H, Zhang L, Wang J (2015) QTL IciMapping: integrated software for genetic linkage map construction and quantitative trait locus mapping in biparental populations. Crop J 3:269-283

Meng L, Lin X, Wang J et al (2013) Simultaneous improvement in cold tolerance and yield of temperate japonica rice (Oryza sativa L.) by introgression breeding. Plant Breed 132:604 612. https://doi.org/10.1111/pbr.12097

Milovanovic V, Smutka L (2017) Asian countries in the global rice market. Acta Univ Agric Silvic Mendelianae Brun 65:679688

Miura K, Lin SY, Yano M, Nagamine T (2001) Mapping quantitative trait loci controlling low temperature germinability in rice (Oryza sativa L.). Breed Sci 51:293-299

Moin M, Bakshi A, Saha A et al (2016) Rice ribosomal protein large subunit genes and their spatio-temporal and stress regulation. Front Plant Sci 7:1284

Murray MG, Thompson WF (1980) Rapid isolation of high molecular weight plant DNA. Nucleic Acids Res 8:4321-4326

Murugaiyan V, Ali J, Mahender A et al (2019) Mapping of genomic regions associated with arsenic toxicity stress in a backcross breeding populations of rice (Oryza sativa L.). Rice 12:61 doi.org/10.1186/s12284-019-0321-y

Mutuku JM, Yoshida S, Shimizu T, Ichihashi Y, Wakatake T, Takahashi A, Seo M, Shirasu K (2015) The WRKY45dependent signaling pathway is required for resistance against Striga hermonthica parasitism. Plant Physiol 168: $1152-1163$

Nagai T, Makino A (2009) Differences between rice and wheat in temperature responses of photosynthesis and plant growth. Plant Cell Physiol 50:744-755

Nagano K (1998) Development of new breeding techniques for cold tolerance and breeding of new rice cultivars with highly cold tolerance, Hitomebore and Jyoudeki. In: Proceedings of the International Workshop on Breeding and Biotechnology for Environmental Stress in Rice, pp 143-148

Najeeb S, Mahender A, Anandan A, et al (2019) Low-temparature stress tolerance in rice: achievements and shortcomings. Rice RICE-D-18-00168 (Unpublished)

Nayar S, Sharma R, Tyagi AK, Kapoor S (2013) Functional delineation of rice MADS29 reveals its role in embryo and endosperm development by affecting hormone homeostasis. J Exp Bot 64:4239-4253

Oikawa K, Kasahara M, Kiyosue T, Kagawa T, Suetsugu N, Takahashi F, Kanegae T, Niwa Y, Kadota A, Wada M (2003) Chloroplast unusual positioning1 is essential for proper chloroplast positioning. Plant Cell 15:2805-2815

Pan Y, Zhang H, Zhang D, Li J, Xiong H, Yu J, Li J, Rashid MA, Li G, Ma X, Cao G, Han L, Li Z (2015) Genetic analysis of cold tolerance at the germination and booting stages in rice by association mapping. PLoS One 10:e120590. https://doi. org/10.1371/journal.pone.0120590

Pang Y, Chen K, Wang X et al (2017) Simultaneous improvement and genetic dissection of salt tolerance of rice (Oryza sativa L.) by designed QTL pyramiding. Front Plant Sci 8:1275. https://doi.org/10.3389/fpls.2017.01275 
Park IK, Oh CS, Kim DM et al (2013) QTL mapping for cold tolerance at the seedling stage using introgression lines derived from an intersubspecific cross in rice. Plant Breed Biotech 1:1-8. https://doi.org/10.9787/PBB.2013.1.1.001

Peremyslov VV, Morgun EA, Kurth EG, et al (2013) Identification of myosin XI receptors in Arabidopsis defines a distinct class of transport vesicles. Plant Cell 25:3022:38. doi: https://doi. org/10.1105/tpc.113.113704

Pouramir DF, Khajeh HM, Esfahani M (2013) Methods for rice genotypes cold tolerance evaluation at germination stage. Int J Agric Crop Sci 5:2111-2116

Pradhan S, Rani KJ (2017) Screening techniques to measure cold tolerance in rice. J Pharmacogn Phytochem 6:781-785

Qian D, Tian L, Qu L (2015) Proteomic analysis of endoplasmic reticulum stress responses in rice seeds. Sci Rep 5:14255

Ranawake AL, Manangkil OE, Yoshida S, Ishii T, Mori N, Nakamura C (2014) Mapping QTLs for cold tolerance at germination and the early seedling stage in rice (Oryza sativa L.). Biotechnol Biotechnol Equip 28:989-998. https://doi. org/10.1080/13102818.2014.978539

Rejeb IB, Pastor V, Mauch-Mani B (2014) Plant responses to simultaneous biotic and abiotic stress: molecular mechanisms. Plants 3:458-475

Rieseberg LH, Widmer A, Arntz AM, Burke B (2003) The genetic architecture necessary for transgressive segregation is common in both natural and domesticated populations. Philos Trans R Soc London B Biol Sci 358:1141-1147

Saha A, Das S, Moin M et al (2017) Genome-wide identification and comprehensive expression profiling of ribosomal protein small subunit (RPS) genes and their comparative analysis with the large subunit (RPL) genes in rice. Front Plant Sci $8: 1553$

Sahebi M, Hanafi MM, Rafii MY, et al (2018) Improvement of drought tolerance in rice (Oryza sativa L.): genetics, genomic tools, and the WRKY gene family. Biomed Res Int 3158474. doi: https://doi.org/10.1155/2018/3158474

Saito K, Hayano-Saito Y, Kuroki M, Sato Y (2010) Map-based cloning of the rice cold tolerance gene Ctb1. Plant Sci 179: 97-102. https://doi.org/10.1016/j.plantsci.2010.04.004

Saito K, Miura K, Nagano K et al (2001) Identification of two closely linked quantitative trait loci for cold tolerance on chromosome 4 of rice and their association with anther length. Theor Appl Genet 103:862-868

Sales E, Viruel J, Domingo C, Marqués L (2017) Genome wide association analysis of cold tolerance at germination in temperate japonica rice (Oryza sativa L.) varieties. PLoS One 12: e0183416

Sanghera GS, Wani SH, Hussain W, Singh NB (2011) Engineering cold stress tolerance in crop plants. Curr Genomics 12:30-43. https://doi.org/10.2174/138920211794520178

Satoh T, Tezuka K, Kawamoto T, Matsumoto S, Satoh-Nagasawa N, Ueda K, Sakurai K, Watanabe A, Takahashi H, Akagi H (2016) Identification of QTLs controlling low-temperature germination of the east European rice (Oryza sativa L.) variety Maratteli. Euphytica 207:245-254. https://doi. org/10.1007/s10681-015-1531-z

Schläppi MR, Jackson AK, Eizenga GC, Wang A, Chu C, Shi Y, Shimoyama N, Boykin DL (2017) Assessment of five chilling tolerance traits and GWAS mapping in rice using the USDA mini-core collection. Front Plant Sci 8:957. https://doi.org/10.3389/fpls.2017.00957
Shakiba E, Edwards JD, Jodari F, Duke SE, Baldo AM, Korniliev P, McCouch S, Eizenga GC (2017) Genetic architecture of cold tolerance in rice (Oryza sativa) determined through high resolution genome-wide analysis. PLoS One 12:e172133. https://doi.org/10.1371/journal.pone.0172133

Sharma N, Dang TM, Singh N, Ruzicic S, Mueller-Roeber B, Baumann U, Heuer S (2018) Allelic variants of OsSUB1A cause differential expression of transcription factor genes in response to submergence in rice. Rice 11:2. https://doi. org/10.1186/s12284-017-0192-Z

Sharma R, Agarwal P, Ray S, Deveshwar P, Sharma P, Sharma N, Nijhawan A, Jain M, Singh AK, Singh VP, Khurana JP, Tyagi AK, Kapoor S (2012) Expression dynamics of metabolic and regulatory components across stages of panicle and seed development in indica rice. Funct Integr Genomics 12:229248. https://doi.org/10.1007/s10142-012-0274-3

Shinada H, Iwata N, Sato T, Fujino K (2014) QTL pyramiding for improving of cold tolerance at fertilization stage in rice. Breed Sci 63:483-488. https://doi.org/10.1270/jsbbs.63.483

Shirasawa S, Endo T, Nakagomi K, Yamaguchi M, Nishio T (2012) Delimitation of a QTL region controlling cold tolerance at booting stage of a cultivar,'Lijiangxintuanheigu', in rice, Oryza sativa L. Theor Appl Genet 124:937-946

Singh A, Jha SK, Bagri J, Pandey GK (2015) ABA inducible rice protein phosphatase $2 \mathrm{C}$ confers $\mathrm{ABA}$ insensitivity and abiotic stress tolerance in Arabidopsis. PLoS One 10:e0125168

Singh B, Singh A, Ngasepam T et al (2016) QTL Mapping for cold tolerance at the seedling stage in rice. Int J Bio-resource Stress Manag 7:1214-1224. https://doi.org/10.5958/09764038.2016.00183.4

Singhal P, Jan AT, Azam M, Haq QMR (2016) Plant abiotic stress: a prospective strategy of exploiting promoters as alternative to overcome the escalating burden. Front Life Sci 9:52-63

Sthapit BR, Witcombe JR (1998) Inheritance of tolerance to chilling stress in rice during germination and plumule greening. Crop Sci 38:660-665

Suh JP, Jeung JU, Lee JI, Choi YH, Yea JD, Virk PS, Mackill DJ, Jena KK (2010) Identification and analysis of QTLs controlling cold tolerance at the reproductive stage and validation of effective QTLs in cold-tolerant genotypes of rice (Oryza sativa L.). Theor Appl Genet 120:985-995

Sun J, Yang L, Wang J et al (2018) Identification of a cold-tolerant locus in rice (Oryza sativa L.) using bulked segregant analysis with a next-generation sequencing strategy. Rice 11:24. https://doi.org/10.1186/s12284-018-0218-1

Teng S, Zeng D, Qian Q et al (2001) QTL analysis of rice low temperature germinability. Chin Sci Bull 46:1800-1803

van Campen J, Yaapar MN, Narawatthana S et al (2016) Combined chlorophyll fluorescence and transcriptomic analysis identifies the $\mathrm{P} 3 / \mathrm{P} 4$ transition as a key stage in rice leaf photosynthetic development. Plant Physiol 170:1655-1674. https://doi.org/10.1104/pp.15.01624

van der Biezen EA, Jones JDG (1998) The NB-ARC domain: a novel signalling motif shared by plant resistance gene products and regulators of cell death in animals. Curr Biol 8: R226-R228

Van Nguyen N, Ferrero A (2006) Meeting the challenges of global rice production. Paddy Water Environ 4:1-9. https://doi. org/10.1007/s10333-005-0031-5 
Verma SK, Xalxo MS, Saxena RR, Verulkar SB (2014) Identification of QTLs for cold tolerance at seedling stage in rice (Oryza sativa L.). Indian J Genet 74:86-89

Wang DH, Song W, Wei SW et al (2018) Characterization of the ubiquitin C-terminal hydrolase and ubiquitin-specific protease families in rice (Oryza sativa). Front Plant Sci 9:1636

Wang D, Liu J, Li C, Kang H, Wang Y, Tan X, Liu M, Deng Y, Wang Z, Liu Y, Zhang D, Xiao Y, Wang GL (2016a) Genome-wide association mapping of cold tolerance genes at the seedling stage in rice. Rice 9:61. https://doi. org/10.1186/s12284-016-0133-2

Wang W, Peng S, Chen Q et al (2016b) Effects of pre-sowing seed treatments on establishment of dry direct-seeded early rice under chilling stress. AoB Plants 8:plw074. https://doi. org/10.1093/aobpla/plw074

Wang W, Xu M, Liu X, Tu J (2016c) The rice eukaryotic translation initiation factor 3 subunit e (OseIF3e) influences organ size and pollen maturation. Front Plant Sci 7:1399

Wang Z, Wang J, Bao Y, Wang FH, Zhang HS (2010) Quantitative trait loci analysis for rice seed vigor during the germination stage. J Zhejiang Univ Sci B 11:958-964

Wani SH, Kumar V, Shriram V, Sah SK (2016) Phytohormones and their metabolic engineering for abiotic stress tolerance in crop plants. Crop J 4:162-176

Xiao N, Gao Y, Qian H, Gao Q, Wu Y, Zhang D, Zhang X, Yu L, Li Y, Pan C, Liu G, Zhou C, Jiang M, Huang N, Dai Z, Liang C, Chen Z, Chen J, Li A (2018) Identification of genes related to cold tolerance and a functional allele that confers cold tolerance. Plant Physiol 177:1108-1123

Xiao N, Huang WN, Zhang XX, Gao Y, Li AH, Dai Y, Yu L, Liu GQ, Pan CH, Li YH, Dai ZY, Chen JM (2014) Fine mapping of qRC10-2, a quantitative trait locus for cold tolerance of rice roots at seedling and mature stages. PLoS One 9:e96046. https://doi.org/10.1371/journal.pone.0096046

Xie L, Tan Z, Zhou Y, Xu R, Feng L, Xing Y, Qi X (2014) Identification and fine mapping of quantitative trait loci for seed vigor in germination and seedling establishment in rice. J Integr Plant Biol 56:749-759

Yang P, Smalle J, Lee S, Yan N, Emborg TJ, Vierstra RD (2007) Ubiquitin C-terminal hydrolases 1 and 2 affect shoot architecture in Arabidopsis. Plant J 51:441-457

Yang T, Zhang S, Zhao J et al (2016) Identification and pyramiding of QTLs for cold tolerance at the bud bursting and the seedling stages by use of single segment substitution lines in rice (Oryza sativa L.). Mol Breed 36:96
Ye C, Fukai S, Godwin I et al (2009) Cold tolerance in rice varieties at different growth stages. Crop Pasture Sci 60: 328-338

Ye C, Fukai S, Godwin ID et al (2010) A QTL controlling low temperature induced spikelet sterility at booting stage in rice. Euphytica 176:291-301

Yu S, Li M, Xiao Y et al (2018) Mapping QTLs for cold tolerance at seedling stage using an Oryza sativa $\times$ O. rufipogon backcross inbred line population. Czech J Genet Plant Breed 54:59-64. https://doi.org/10.17221/154/2016-CJGPB

Zeng Y, Zhang Y, Xiang J et al (2017) Effects of low temperature stress on spikelet-related parameters during anthesis in indica-japonica hybrid rice. Front Plant Sci 8:1350

Zhang H, Liu S, Chen G et al (2018a) Genetic dissection of QTLs and differentiation analysis of alleles for heading date genes in rice. PLoS One 13:e0190491

Zhang M, Ye J, Xu Q et al (2018b) Genome-wide association study of cold tolerance of Chinese indica rice varieties at the bud burst stage. Plant Cell Rep 37:529-539

Zhang Q, Chen Q, Wang S, Hong Y, Wang Z (2014a) Rice and cold stress: methods for its evaluation and summary of cold tolerance-related quantitative trait loci. Rice 7:24. https://doi. org/10.1186/s12284-014-0024-3

Zhang S, Zheng J, Liu B et al (2014b) Identification of QTLs for cold tolerance at seedling stage in rice (Oryza sativa L.) using two distinct methods of cold treatment. Euphytica 195:95104

Zhao J, Zhang S, Dong J, Yang T, Mao X, Liu Q, Wang X, Liu B (2017) A novel functional gene associated with cold tolerance at the seedling stage in rice. Plant Biotechnol J 15:11411148. https://doi.org/10.1111/pbi.12704

Zhou L, Zeng Y, Zheng W et al (2010) Fine mapping a QTL qCTB7 for cold tolerance at the booting stage on rice chromosome 7 using a near-isogenic line. Theor Appl Genet 121: 895-905

Zhu Y, Chen K, Mi X, Chen T, Ali J, Ye G, Xu J, Li Z (2015) Identification and fine mapping of a stably expressed QTL for cold tolerance at the booting stage using an interconnected breeding population in rice. PLoS One 10:e0145704. https://doi.org/10.1371/journal.pone.0145704

Publisher's note Springer Nature remains neutral with regard to jurisdictional claims in published maps and institutional affiliations. 